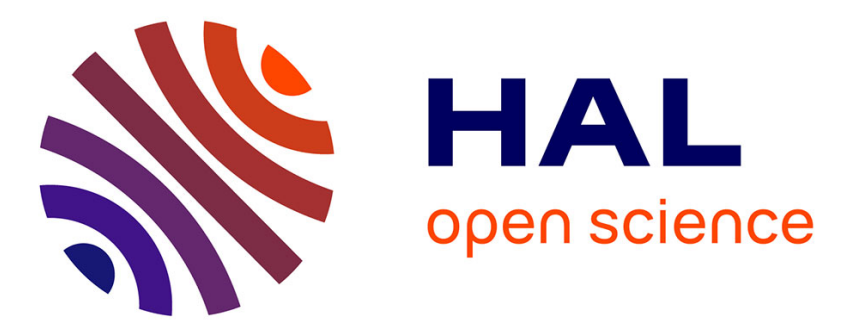

\title{
From uni- to multi-axial fretting-fatigue crack nucleation: Development of a stress-gradient-dependent critical distance approach
}

Siegfried Fouvry, Hervé Gallien, Bruno Berthel

\section{- To cite this version:}

Siegfried Fouvry, Hervé Gallien, Bruno Berthel. From uni- to multi-axial fretting-fatigue crack nucleation: Development of a stress-gradient-dependent critical distance approach. International Journal of Fatigue, 2014, 62, pp.194-209. 10.1016/j.ijfatigue.2013.05.016 hal-01524456

\author{
HAL Id: hal-01524456 \\ https://hal.science/hal-01524456
}

Submitted on 18 May 2017

HAL is a multi-disciplinary open access archive for the deposit and dissemination of scientific research documents, whether they are published or not. The documents may come from teaching and research institutions in France or abroad, or from public or private research centers.
L'archive ouverte pluridisciplinaire HAL, est destinée au dépôt et à la diffusion de documents scientifiques de niveau recherche, publiés ou non, émanant des établissements d'enseignement et de recherche français ou étrangers, des laboratoires publics ou privés. 


\section{Accepted Manuscript}

From uni- to multi-axial fretting-fatigue crack prediction: development of a stress-gradient-dependent critical distance approach

S. Fouvry, H. Gallien, B. Berthel

PII:

S0142-1123(13)00165-5

DOI: http://dx.doi.org/10.1016/j.ijfatigue.2013.05.016

Reference: JIJF 3136

To appear in:

International Journal of Fatigue

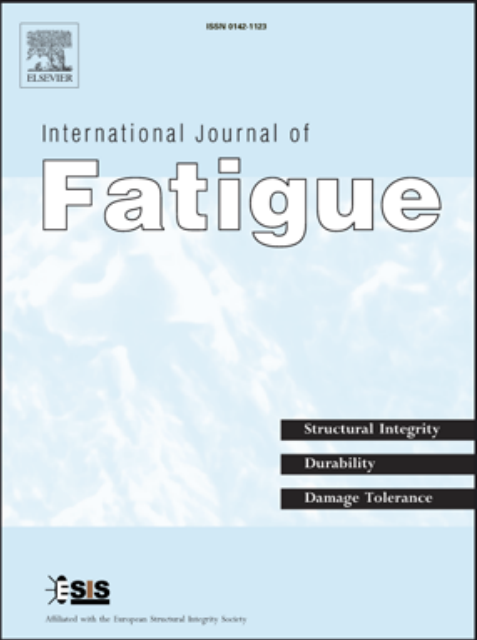

Received Date:

9 November 2012

Revised Date:

14 May 2013

Accepted Date:

28 May 2013

Please cite this article as: Fouvry, S., Gallien, H., Berthel, B., From uni- to multi-axial fretting-fatigue crack prediction: development of a stress-gradient-dependent critical distance approach, International Journal of Fatigue (2013), doi: http://dx.doi.org/10.1016/j.ijfatigue.2013.05.016

This is a PDF file of an unedited manuscript that has been accepted for publication. As a service to our customers we are providing this early version of the manuscript. The manuscript will undergo copyediting, typesetting, and review of the resulting proof before it is published in its final form. Please note that during the production process errors may be discovered which could affect the content, and all legal disclaimers that apply to the journal pertain. 


\title{
From uni- to multi-axial fretting-fatigue crack prediction: development of a
} stress-gradient-dependent critical distance approach

\author{
S. Fouvry*, H. Gallien, B. Berthel \\ Ecole Centrale de Lyon, 36, Avenue Guy de Collongue F-69134 Ecully, Cedex \\ LTDS, CNRS, Ecole Centrale de Lyon, Ecully 69134 Cedex, France \\ :Corresponding author (siegfried.fouvry@ec-lyon.fr)
}

\begin{abstract}
Fretting fatigue is characterized by combined high stress gradients induced by contact loading and more homogeneous stress gradients induced by bulk fatigue stressing. The stress gradients computed at the "hot-spot" located on the surface at the trailing contact border are very high, usually above $10 \mathrm{GPa} / \mathrm{mm}$. For such uncommon stressing conditions, prediction of cracking risk becomes very complex and non-local fatigue approaches must be adopted. The purpose of the present study was to investigate how non-local strategies, such as "critical distance", developed for medium stress gradient conditions such as "notch" configurations, were transposed to predict fretting cracking risk. Elastic crack nucleation conditions of a 35 Ni Cr Mo 16 low alloyed steel at 10E6 cycles have been identified for various cylinder pad radius, contact pressure and fatigue stress conditions. The experimental crack nucleation conditions were then compared to predictions from analytical simulations coupling uni-axial and Crossland's multiaxial fatigue descriptions. The local "hot-spot" analysis systematically overestimated cracking risk and induced more than $30 \%$ error with respect to the experimental values. The non-local "critical distance method" based on a constant length scale value still displayed more than $10 \%$ dispersion suggesting that a non constant "critical distance" approach must be considered. By expressing the critical distance evolution as a function of the hydrostatic stress gradient operating next to the stress hot-spot, dispersion was reduced below 5\%. Established for the Crossland's stress invariant formulation, this tendency is confirmed by comparing McDiarmid and MWCM critical plane fatigue approaches.
\end{abstract}

Keywords: Fretting Fatigue Map, Crack nucleation, Stress gradient, Crossland - McDiarmid -MWCM fatigue criteria, Non local fatigue approach. 


\section{Introduction}

Fretting is a small-amplitude oscillatory movement which may occur between contacting surfaces that are subject to vibration or cyclic stress. Combined with cyclic bulk fatigue loading, so-called fretting-fatigue loading can induce catastrophic cracking phenomena which critically reduce the endurance of assemblies. Considered a plague for modern industry, fretting-fatigue is encountered in all quasi-static contact loadings subject to vibration and cyclic fatigue, and thus concerns many industrial branches (helicopters, aircraft, trains, ships, trucks, etc...) $[1,2,3]$.

As illustrated in Figure 1, fretting-fatigue loading can be defined as the superimposition of contact stressing characterized by very high stress gradient and quasi-homogeneous fatigue bulk loading. During recent decades, a significant effort has been made to formalize both crack nucleation and crack arrest conditions [4,5]. The crack arrest condition is described by computing the evolution of the stress intensity factor below the interface and by predicting the crack arrest condition using short crack arrest formalisms [5,6]. The crack nucleation phenomenon is commonly addressed by transposing conventional multi-axial fatigue criteria [7]. However, as illustrated in Figure 1, fretting stressing conditions are characterized by very severe stress gradients, which may be one order of magnitude larger than common notch fatigue stress configurations. Non-local fatigue approaches are therefore required to predict cracking risk. Stress averaging approaches [4] or equivalent critical distance methods [5], which consist in considering the stress state at a "critical distance" from the stress "hot-spot", are commonly applied to capture the stress gradient effect $[8,9]$. However, these approaches which consider a fixed length scale value are limited when large stress gradient fluctuations are operating. To palliate such limitations, a new alternative strategy, based on a variable critical distance function of the stress gradient imposed by the contact, is presently being considered. To calibrate this new strategy, the crack nucleation response at $10^{6}$ cycles of a well known 35Ni CrMo16 low-alloyed steel was studied under various plain fretting and fretting fatigue elastic partial slip conditions, covering a wide stress gradient domain.

\section{MATERIAL \& EXPERIMENTS}

\subsection{Materials}

The studied material is a tempered $35 \mathrm{Ni} \mathrm{Cr}$ Mo 16 low-alloyed steel displaying a tempered Martensitic structure. The fatigue and fracture properties of this alloy and equivalent structures were extensively investigated by Galtier and Henaff $[10,11]$. The mechanical and 
fatigue properties are summarized in table 1. Chromium 52100 steel was chosen for the cylindrical pads in order to maintain elastically similar conditions whilst simultaneously ensuring that cracks arose only in plane and fatigue $35 \mathrm{Ni} \mathrm{Cr}$ Mo 16 specimens. Both plane and cylindrical pad surfaces were polished to achieve low $\mathrm{Ra}=0.05 \mu \mathrm{m}$ surface roughness.

\subsection{Test Conditions}

As illustrated in Figure 2, two different test apparatuses were applied to quantify respectively the fretting and the fatigue influences in cracking processes.

\section{Plain fretting test}

Plain fretting tests were applied by imposing a nominally static normal force $\mathrm{P}$, followed by a purely alternating cyclic displacement $(\delta)$, so that an alternating cyclic tangential load Q was generated on the contact surface [4]. During testing, P, Q and $\delta$ were recorded, from which the $\delta$ - Q fretting loop could be plotted; this cycle was characterized respectively by the tangential force amplitude $\left(\mathrm{Q}^{*}\right)$, displacement amplitude $\left(\delta^{*}\right)$, and fiction-dissipated energy (Ed). By analyzing the fretting loop, the sliding condition could be identified and the loading condition adjusted if necessary to maintain a partial slip contact configuration.

\section{Fretting Fatigue test}

The fretting-fatigue experiments were performed using a dual actuator device [12] inspired by Fellows et al. [13] and Lee and Mall's [14] experiments. This test system allowed separate application of fretting and fatigue loadings. Multiple sensors recorded and controlled the contact loads $(\mathrm{Q}, \mathrm{P}, \delta)$ and fatigue stress, defined by maximum tensile stress $\sigma_{\mathrm{fa}, \max }$ also denoted $\sigma_{\mathrm{fa}}$, minimum fatigue tress $\sigma_{\mathrm{fa}, \min }$ and the corresponding fatigue stress ratio $\mathrm{R}_{\mathrm{fa}}=\sigma_{\mathrm{fa}, \text { min }} / \sigma_{\mathrm{fa}}$. One original feature of the set-up developed in our laboratory is its ability to perform single contact fretting fatigue tests using a ball-bearing located at the opposite side of the contact. This system enables the application of a large diversity of combined phase and unphased loadings. In the present investigation, only in-phase loadings were investigated.

\subsection{Experimental test conditions}

The purpose of the study was to investigate fretting fatigue cracking risk, considering numerous aspects such as the effect of contact pressure, the relative influences of contact and fatigue stressing, the fatigue stress ratio and above all contact size and stress gradient effects. Three cylinder radius pads, $\mathrm{R}=20,40$ and $80 \mathrm{~mm}$, were studied, adjusting the normal force to 
investigate three contact pressures, $\mathrm{p}_{\max }=600,800$ and $1000 \mathrm{MPa}$. This extensive plain fretting analysis was then transposed to fretting fatigue conditions by superimposing three maximum fatigue stresses $\sigma_{\mathrm{fa}}=100,200$ and $400 \mathrm{MPa}$, considering two stress ratio conditions, $\mathrm{R}_{\mathrm{fa}}=0.1$ and 1 (i.e., pre-stressed conditions). The applied conditions are compiled in Table II and illustrated in Figure 3. The Hertzian contact radius varied from a $=0.28$ to $1.4 \mathrm{~mm}$. The lateral width $(\mathrm{L})$ of the cylinder pads was adjusted to maintain near plain strain conditions along the median axis $(\mathrm{a} / \mathrm{L}<0.15)$. All the study was performed at 13 $\mathrm{Hz}$.

\subsection{Experimental results}

\section{Friction analysis}

To compute the contact stress field, it is necessary first to identify the coefficient of friction operating in the sliding zones of the partial slip interface. H. Proudhon et al. showed that the friction coefficient measured at the transition between partial and gross slip conditions $\left(\mu_{\mathrm{t}}\right)$ may be used to provide a representative value of the friction under partial slip conditions (i.e. $\mu_{\mathrm{PS}}=\mu_{\mathrm{t}}$ ) [15]. To determine this value, a variable displacement method was applied keeping the normal load constant whilst the relative displacement amplitude $\left(\delta^{*}\right)$ is progressively increased (Fig. 4a). For a 2D cylinder/plane configuration, the sliding transition is marked by discontinuity of the tangential force ratio $\left(\mathrm{Q}^{*} / \mathrm{P}\right)$ and friction energy ratio $\mathrm{A}=\mathrm{Ed} /\left(4 . \mathrm{Q}^{*} . \delta^{*}\right)$. Figure $4 \mathrm{~b}$ compares the evolution of $\mu_{\mathrm{t}}$ versus the Hertzian contact radius for different contact pressures. Evolution is almost constant, which suggests that, for the studied condition, a constant partial slip friction value can be assumed: $\mu=\mu_{P S}=\bar{\mu}_{t}=0.8$.

\section{Experimental identification of the crack nucleation condition}

Cracking investigation consisted in identifying the fretting loading inducing a threshold crack length after $10^{6}$ cycles. The following methodology was applied: After each fretting test, the plane specimen was cut along the median axis of the fretting scar. Cross section observations were performed, and not only the real crack length $\left(b_{r}\right)$, but also the projected crack length $\left(b_{p}\right)$ along the normal of the surface were measured (Fig. 5a). The polishing process was then repeated twice so that the crack measurement was performed on 6 different planes located along the median axis of the fretting scar. From these 6 measurements, the maximum projected crack length $\left(b_{\mathrm{p}, \max }\right)$ was determined. This crack analysis was generalized to various tangential force amplitudes in order to plot the evolution of $b_{p, \max }$ as a function of the applied 
tangential force amplitude (Fig. 5b). Finally, the threshold crack nucleation $\mathrm{Q}_{\mathrm{CN}}^{*}$ was determined by extrapolating the tangential force amplitude related to a $b_{\text {pth }}=10 \mu \mathrm{m}$ projected crack length. From 6 to 8 tests are usually required to estimate the threshold crack nucleation value with dispersion less than $+/-5 \mathrm{~N} / \mathrm{mm}$. More than one 100 fretting experiments were performed to compile the given fretting fatigue crack nucleation conditions $Q_{C N}^{*}$ (Table II). Cross-section examinations showed that incipient crack nucleation was systematically observed at the contact borders for plain fretting conditions or at the trailing contact border (i.e., specimen side where fatigue loading is imposed) for fretting fatigue conditions. Crack nucleation conditions corresponded to established partial slip conditions (i.e., Table II), leading to negligible surface wear, which was confirmed by 3D surface profiles. Therefore the contact geometry could be assumed to be unchanged during the fretting test.

\section{CONTACT STRESS ANALYSIS}

The studied conditions were elastic, so that the Hertz, Mindlin and McEven [16, 17, 18] formalisms could be considered as establishing the fretting contact stress distributions $\left(\underline{\underline{\Sigma}}_{\mathrm{fr}}(\mathrm{t})\right)$. Adding the in-phase fatigue stressing $\left({\underline{\underline{\Sigma_{\mathrm{fa}}}}}_{\mathrm{a}}(\mathrm{t})\right)$, the total fretting fatigue loading path is expressed by:

$\underline{\underline{\Sigma}}(\mathrm{t})=\underline{\underline{\Sigma}}_{\mathrm{fr}}(\mathrm{t})+\underline{\underline{\underline{\Sigma}}}_{\mathrm{fa}}(\mathrm{t})$

For quasi-static partial slip conditions, the contact stress field was itself defined as the sum of a constant pressure component and an alternating shear component:

$\underline{\underline{E}}_{\mathrm{fr}}(\mathrm{t})=\underline{\underline{\Sigma}}_{\mathrm{P}}+\sum_{\underline{Q}} \mathrm{Q}(\mathrm{t})$

For the plain fretting situation, the fatigue component disappears so that:

$\underline{\underline{\Sigma}}(\mathrm{t})={\underline{\underline{\sum_{\mathrm{fr}}}}}_{\mathrm{f}}(\mathrm{t})$.

The following analysis details some aspects of the Mindlin - McEven description.

\section{Surface pressure and shear distribution.}

\section{Pressure field}

The Hertzian formalism is applied according that fretting and fretting-fatigue specimen thicknesses $(\mathrm{t}=10 \mathrm{~mm})$ were assumed to be sufficient compared to the contact radius $(\mathrm{t} / \mathrm{a}>10)$, so that no thickness corrections were required. Elastic half space hypotheses were considered and the contact pressure profile was assumed to be constant and immobile due to the partial slip conditions. A 2D plain strain cylinder/plane Hertzian formalism was applied: 
$p(x)=p_{0}\left(1-\left(\frac{x}{a}\right)^{2}\right)^{1 / 2}$

with $\mathrm{a}$, the Hertzian contact radius, and $\mathrm{p}_{0}=\mathrm{p}_{\max }$ the maximum contact pressure operating at the center of the interface $(x=0)$ :

$$
\begin{aligned}
& \mathrm{a}=\left(\frac{4 \mathrm{PR}}{\pi \mathrm{E}^{*}}\right)^{1 / 2} \text { with } \frac{1}{\mathrm{E}^{*}}=\frac{1-v_{1}^{2}}{\mathrm{E}_{1}}+\frac{1-v_{1}^{2}}{\mathrm{E}_{1}} \\
& \mathrm{p}_{0}=\mathrm{p}_{\max }=\frac{2 \mathrm{P}}{\pi \mathrm{a}}=\left(\frac{\mathrm{P} \cdot \mathrm{E}^{*}}{\pi \mathrm{R}}\right)^{1 / 2}
\end{aligned}
$$

with $\mathrm{P}$, the linear applied normal force $(\mathrm{N} / \mathrm{mm}), \mathrm{R}$ the radius of the cylinder pad, $\mathrm{E}_{1}=\mathrm{E}$ and $\mathrm{E}_{2}$, the Young's modulus of plane and pad respectively, and $\mathrm{v}_{1}=\mathrm{v}$ and $\mathrm{v}_{2}$ the Poisson's coefficient of plane and pad respectively.

\section{Surface shear distribution}

\section{Plain fretting and pre-stressed fretting condition.}

Without cyclic fatigue loading, the shear distribution in the interface is symmetrical and can be expressed using the conventional Mindlin formalism. The partial slip contact consists of central inner stick domain bordered by two lateral sliding zones. During the fretting cycle the slip boundary (c') pulses from the external contact border (a) to the inner stick (c) radius (i.e., $\left.: c^{\prime}: \mathrm{a} \rightarrow \mathrm{c}\right)$. At loading $\left(\mathrm{Q}=+\mathrm{Q}^{*}\right)$ and unloading $\left(\mathrm{Q}=-\mathrm{Q}^{*}\right)$ amplitudes, the surface shear profiles are simplified to:

$$
\mathrm{q}_{+\mathrm{Q}^{*}}(\mathrm{x}, \mathrm{a}, \mathrm{c})=\left|+\mathrm{q}_{0}\left[\left(1-\left(\frac{\mathrm{x}}{\mathrm{a}}\right)^{2}\right)^{1 / 2}-\mathrm{k}\left(1-\left(\frac{\mathrm{x}}{\mathrm{c}}\right)^{2}\right)^{1 / 2}\right],\right| \mathrm{x} \mid \leq \mathrm{c}
$$

$$
+q_{0}\left(1-\left(\frac{x}{a}\right)^{2}\right)^{1 / 2}, c \leq|x| \leq a
$$

and $\mathrm{q}_{-\mathrm{Q}^{*}}(\mathrm{x}, \mathrm{a}, \mathrm{c})=-\mathrm{q}_{+\mathrm{Q}^{*}}(\mathrm{x}, \mathrm{a}, \mathrm{c})$

with $\mathrm{k}=\frac{\mathrm{c}}{\mathrm{a}}=\left(1-\frac{\mathrm{Q}^{*}}{\mu \mathrm{P}}\right)^{1 / 2}$ and $\mathrm{q}_{0}=\mu \mathrm{p}_{0}$,

As developed in [17], the surface shear profiles can be expressed using an adequate superimposition of a global full sliding $\left(a, q_{0}\right)$ and stick $\left(c, \frac{c}{a} q_{0}\right)$ elliptical components (Fig. 
6). The maximum shear value $\mathrm{q}_{\max }$ which is observed at the stick boundaries $(|\mathrm{x}|=\mathrm{c})$ is expressed by:

$$
\mathrm{q}_{\max }=\mathrm{q}_{0}\left(1-\mathrm{k}^{2}\right)^{1 / 2}
$$

\section{Fretting-Fatigue loading $\left(R_{f a}<1\right)$}

A similar Mindlin strategy was applied to describe the surface shear profile during cyclic fretting fatigue. However, Nowell et al. [19] demonstrated that the bulk loading which is present in the fatigue specimen but not in the pad specimen promotes a strain mismatch in the contact zone, which induces a shift of the stick zone. This shift is quantified by an "eccentricity" length e. For the specific conditions where e+c $\leq \mathrm{a}$, an explicit expression can be achieved:

$$
\mathrm{e}=\frac{\sigma \cdot \mathrm{a}}{4 \cdot \mu \cdot \mathrm{p}_{0}} \text { or } \mathrm{h}=\frac{\mathrm{e}}{\mathrm{a}}=\frac{\sigma}{4 \cdot \mathrm{q}_{0}}
$$

In the present experimental investigation, the contact was adjusted after the mean fatigue stress was applied, which implies that the stress variation involved in equation (11) corresponded to the fatigue stress amplitude, which in turn implies:

$$
\mathrm{h}=\frac{1}{8 \mathrm{q}_{0}} \sigma_{\mathrm{fa}}\left(1-\mathrm{R}_{\mathrm{fa}}\right)
$$

This eccentricity (i.e., offset) of the stick zone induces a dissymmetry in the shear stress field distribution. If larger bulk stresses are applied, (i.e., $\mathrm{h}+\mathrm{k}>1$ ), a complex reverse slip process takes place within the interface. In the present investigation, all the studied crack nucleation conditions were observed for non-reverse slip conditions (i.e., $\mathrm{h}+\mathrm{k} \leq 1$ ). As previously, Mindlin's description of the surface shear stress field distributions was defined by summing the contribution of the global contact, stick zone and pulsing sliding elliptical shear stress field components but taking into account the eccentricity shift (Fig. 6). Restricting analysis to the loading $\left(+\mathrm{Q}^{*}\right)$ and unloading $\left(-\mathrm{Q}^{*}\right)$ amplitude situations we have:

$$
\mathrm{q}_{+\mathrm{Q}^{*}}(\mathrm{x}, \mathrm{a}, \mathrm{c}, \mathrm{e})=\mid \begin{aligned}
& +\mathrm{q}_{0}\left(1-\left(\frac{\mathrm{x}}{\mathrm{a}}\right)^{2}\right)^{1 / 2},-\mathrm{a} \leq \mathrm{x} \leq-\mathrm{c}+\mathrm{e} \\
& +\mathrm{q}_{0}\left[\left(1-\left(\frac{\mathrm{x}}{\mathrm{a}}\right)^{2}\right)^{1 / 2}-\frac{\mathrm{c}}{\mathrm{a}}\left(1-\left(\frac{\mathrm{x}-\mathrm{e}}{\mathrm{c}}\right)^{2}\right)^{1 / 2}\right],-\mathrm{c}+\mathrm{e} \leq \mathrm{x} \leq \mathrm{c}+\mathrm{e} \\
& +\mathrm{q}_{0}\left(1-\left(\frac{\mathrm{x}}{\mathrm{a}}\right)^{2}\right)^{1 / 2}, \mathrm{c}-\mathrm{e} \leq \mathrm{x} \leq \mathrm{a}
\end{aligned}
$$


and $\mathrm{q}_{-\mathrm{Q}^{*}}(\mathrm{x}, \mathrm{a}, \mathrm{c}, \mathrm{e})=-\mathrm{q}_{+\mathrm{Q}^{*}}(\mathrm{x}, \mathrm{a}, \mathrm{c}, \mathrm{e})$

The shear profile was no longer symmetrical and the maximum shear value was observed at the stick boundary of the trailing contact side $(x=-c+e)$ :

$\mathrm{q}_{\max }=\mathrm{q}_{0}\left(1-\left(\frac{\mathrm{c}-\mathrm{e}}{\mathrm{a}}\right)^{2}\right)^{1 / 2}=\mathrm{q}_{0}\left(1-(\mathrm{k}-\mathrm{h})^{2}\right)^{1 / 2}$ with $\mathrm{k}+\mathrm{h} \leq 1$

The maximum shear related to the limiting reverse-slip condition $(\mathrm{k}+\mathrm{h}=1)$ is given by:

$\mathrm{q}_{\text {max } \mathrm{RS}}=\sigma_{\mathrm{fa}}\left(\frac{\mathrm{q}_{0}}{\sigma_{\mathrm{fa}}}-\frac{1}{4}\right)^{1 / 2}$

\subsection{Subsurface stress field distribution}

The subsurface stress loading paths were computed by coupling the above Mindlin pressure and shear formalism with the McEven formulations [18]. For the general fretting fatigue situation, contact stress analysis needs to consider the eccentricity "e" induced by cyclic fatigue loading. If both fretting and fatigue loading are collinear and in phase, stress analysis can be restricted to the trailing side of the contact $(x<0)$. Focusing on the two maximum "loading" and minimum "unloading" stages, the total maximum and minimum fretting fatigue stresses are expressed by:

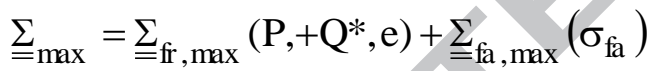

$\sum_{\text {min }}=\sum_{\underline{\sum_{\mathrm{f}}, \min }}\left(\mathrm{P},-\mathrm{Q}^{*}, \mathrm{e}\right)+{\underline{\underline{\sum_{\mathrm{fa}}, \min }}}\left(\mathrm{R}_{\mathrm{fa}} \cdot \sigma_{\mathrm{fa}}\right)$

Figure 7 a plots the surface profile distribution of the maximum principal stress $\left(\sigma_{1, \max }\right)$ and Tresca shear $\left(T_{\max }\right)$ imposed during the representative FF2 fretting fatigue test condition (Table II). From this contact stress analysis, it can be concluded that the most severe stress loading paths were imposed at the trailing contact border (i.e. $\mathrm{x}=-\mathrm{a}, \mathrm{z}=0$ ). At this particular position, the stress state is bi-axial according to the plain strain hypothesis, but just outside this hot-spot location the stress state was clearly multi-axial (Fig. 7b). Focusing on the trailing contact border (TCB: $\mathrm{x}=-\mathrm{a}, \mathrm{z}=0$ ), where the maximum stressings are imposed and where the incipient cracking processes are observed, we demonstrate by coupling Mindlin's and McEven's formalisms that the contact stress components is expressed by :

$$
\underline{\underline{\Sigma}}_{\mathrm{fr}, \max }=\underline{\underline{\Sigma}}_{\mathrm{fr}, \mathrm{a}}=\mid \begin{aligned}
& \sigma_{11 \mathrm{fr}}=\sigma_{1 \mathrm{fr}, \max }=\sigma_{1 \mathrm{fr}, \mathrm{a}}=\sigma_{\mathrm{fr}}=2 \cdot \mathrm{q}_{0}\left(\left((1+\mathrm{h})^{2}-\mathrm{k}^{2}\right)^{1 / 2}-\mathrm{h}\right) \\
& \sigma_{22 \mathrm{fr}}=v \cdot \sigma_{\mathrm{fr}}
\end{aligned}
$$

with $\mathrm{h}+\mathrm{k} \leq 1$. 
Indeed, at the contact border, the pressure stress components disappear and contact stress is function only of the cyclic tangential stress components. At this specific position, contact stress is quasi-uniaxial (i.e., biaxial assuming the plain strain hypothesis) and alternating. It is noteworthy to note that the driving contact stress $\sigma_{\text {fr }}$ (18), can be expressed as a function of the maximum interfacial shear stress. Indeed, coupling (15) and (18) showed that:

$$
\sigma_{\text {fr }}=2 \cdot q_{\max } \cdot f(h, k) \text { with } f(h, k)=\left[\left(\frac{1+k+h}{1+k-h}\right)^{1 / 2}-\frac{h}{\left(1-(k-h)^{2}\right)^{1 / 2}}\right] \text {. }
$$

Parametric analysis for non-reverse slip conditions (i.e. $h+k \leq 1$ ) showed that, for $h$ values between 0.5 and 0.95 and $\mathrm{k}$ ratio ranging from 0 to 0.95 , the $\mathrm{f}(\mathrm{h}, \mathrm{k})$ function varied from 0.86 up to 3.2. However, if $h=0$, the $f(h, k)$ function was constant and equal to 1 whatever the $k$ value. Hence, for plain fretting or pre-stressed fretting fatigue $\left(\mathrm{R}_{\mathrm{fa}}=1\right)$ configurations, contact stress was proportional to maximum interfacial shear:

$\sigma_{\mathrm{fr}}=2 . \mathrm{q}_{\max }$

Finally, the total fretting fatigue stress field was provided by summing contact and fatigue stress components. The maximum stressing at the trailing contact border is expressed by:

$$
\sum_{\max }=\mid \begin{aligned}
& \sigma_{11, \max }=\sigma_{\mathrm{fr}}+\sigma_{\mathrm{fa}} \\
& \sigma_{22, \max }=v \cdot \sigma_{11, \max }
\end{aligned}
$$

So that the maximum principal stress and Tresca shear are expressed by:

$$
\sigma_{1, \text { max }}=2 . \mathrm{T}_{\max }=\sigma_{11, \max }=2 \cdot \mathrm{q}_{0}\left(\left((1+\mathrm{h})^{2}-\mathrm{k}^{2}\right)^{1 / 2}-\mathrm{h}\right)+\sigma_{\mathrm{fa}}
$$

The Von Mises stresses at the critical stress "hot-spot" is given by:

$$
\sigma_{\mathrm{VM}, \max }=\sigma_{1, \max }\left(1+v^{2}-v\right)^{1 / 2}=\left[2 \mathrm{q}_{0}\left(\left((1+\mathrm{h})^{2}-\mathrm{k}^{2}\right)^{1 / 2}-\mathrm{h}\right)+\sigma_{\mathrm{fa}}\right]\left(1+v^{2}-v\right)^{1 / 2}
$$

The threshold contact stresses related to the Tresca and Von Mises plastic yields are:

$$
\sigma_{\mathrm{fr}_{-} \mathrm{T}}=2 \tau_{\mathrm{y}}-\sigma_{\mathrm{fa}} \text { and } \sigma_{\mathrm{fr}_{-} \mathrm{VM}}=\frac{\sigma_{\mathrm{y}}}{\left(1+v^{2}-v\right)^{1 / 2}}-\sigma_{\mathrm{fa}}
$$

The contact stress related to the reverse-slip boundary condition is expressed by:

$$
\sigma_{\mathrm{fr}_{-} \mathrm{RS}}=2 \mathrm{q}_{0}(2 \sqrt{\mathrm{h}}-\mathrm{h})=\left(2 \mathrm{q}_{0} \sigma_{\mathrm{fa}}\left(1-\mathrm{R}_{\mathrm{fa}}\right)\right)^{1 / 2}-\frac{\sigma_{\mathrm{fa}}}{4}\left(1-\mathrm{R}_{\mathrm{fa}}\right)
$$

\section{Plain Fretting Condition}


The stress state at the trailing contact for the plain fretting condition is directly defined from the previous expressions, putting $\mathrm{h}=0$ and $\sigma_{\mathrm{fa}}=0$ :

$$
\underline{\underline{\Sigma}}_{\max }=\underline{\underline{\Sigma}}_{\mathrm{fr}, \max }=\underline{\underline{\Sigma}}_{\mathrm{fr}, \mathrm{a}}=\mid \begin{aligned}
& \sigma_{11 \mathrm{fr}}=\sigma_{1 \mathrm{fr}, \max }=\sigma_{1, \max }=\sigma_{\mathrm{fr}}=2 \cdot \mathrm{q}_{\max }=2 \mathrm{q}_{0}\left(1-\mathrm{k}^{2}\right)^{1 / 2} \\
& \sigma_{22 \mathrm{fr}}=v \cdot \sigma_{\mathrm{fr}}
\end{aligned}
$$

Tresca shear and Von Mises stress are simplified to:

$$
\mathrm{T}_{\max }=\frac{\sigma_{\mathrm{fr}}}{2} \text { and } \sigma_{\mathrm{VM}, \max }=\sigma_{\mathrm{fr}}\left(1+v^{2}-v\right)^{1 / 2}
$$

so that the contact plastic yield limits are expressed respectively by:

$$
\sigma_{\mathrm{fr}_{-} \mathrm{T}}=2 \cdot \mathrm{q}_{\mathrm{max}_{-} \mathrm{T}}=2 \tau_{\mathrm{y}} \text { and } \sigma_{\mathrm{fr}_{-} \mathrm{VM}}=2 \cdot \mathrm{q}_{\mathrm{max}_{-} \mathrm{VM}}=\frac{\sigma_{\mathrm{y}}}{\left(1+v^{2}-v\right)^{1 / 2}}
$$

\section{Crossland multiaxial criterion}

Except at the trailing contact border, the contact stressing is highly multiaxial (Fig. 7b). The Crossland's multiaxial fatigue approach was used being well adapted to describe the fatigue response of the studied alloy [20]. The crack risk was expressed as a linear combination of the square root of the maximum amplitude of the second stress invariant $\left(\sqrt{\mathbf{J}_{2, a}}\right)$, and the maximum hydrostatic stress value $\left(\sigma_{\mathrm{H}, \max }\right)$. The non cracking condition was expressed by :

$$
\sqrt{\mathbf{J}_{2, \mathrm{a}}}+\alpha_{\mathrm{C}} \cdot \sigma_{\mathrm{H}, \max }<\tau_{\mathrm{d}}
$$

where

$$
\begin{aligned}
& \sigma_{\mathrm{H}, \max }=\max _{\mathrm{t} \in \mathrm{T}}\left(\frac{1}{3} \operatorname{trace}(\underline{\underline{\underline{\Sigma}}}(\mathrm{t}))\right), \\
& \sqrt{\mathrm{J}_{2, \mathrm{a}}}=\frac{1}{2} \max _{\mathrm{t}_{0} \in \mathrm{T}}\left\{\max _{\mathrm{t} \in \mathrm{T}}\left[\frac{1}{2}\left(\underline{\underline{S}}(\mathrm{t})-\underline{\underline{S}}\left(\mathrm{t}_{0}\right)\right):\left(\underline{\underline{S}}(\mathrm{t})-\underline{\underline{S}}\left(\mathrm{t}_{0}\right)\right)\right]^{1 / 2}\right\}, \\
& \alpha_{\mathrm{C}}=\frac{\tau_{\mathrm{d}}-\sigma_{\mathrm{d}} / \sqrt{3}}{\sigma_{\mathrm{d}} / 3},
\end{aligned}
$$

with, $\underline{\underline{S}}$, the deviatoric part of $\underline{\underline{\Sigma}}$. From the fatigue values given in Table $1, \alpha_{C}=0.28$. The cracking risk was estimated by comparing the equivalent Crossland stress

$$
\sigma_{\mathrm{C}}=\sqrt{\mathrm{J}_{2, \mathrm{a}}}+\alpha_{\mathrm{C}} \cdot \sigma_{\mathrm{H}, \max }
$$

versus the torsion fatigue limit:

if $\sigma_{C} \geq \tau_{d}$, there is a cracking risk. 
Figure 8 shows the normalized distribution of $\sigma_{\mathrm{C}}$, applying local fatigue stress analysis for the representative FF2 fretting fatigue crack nucleation condition (Table II). As expected from the previous stress analysis, the maximum equivalent Crossland stress value $\sigma_{\mathrm{C} \text {,max }}$ was located at the trailing contact border, and characterized by very sharp gradients. At this critical position, the maximum Crossland equivalent stress can be expressed using an explicit formulation where:

$$
\begin{aligned}
& \sqrt{\mathrm{J}_{2, \mathrm{a}}}=\mathrm{A}\left(\sigma_{\mathrm{fr}}+\frac{\sigma_{\mathrm{fa}}}{2}\left(1-\mathrm{R}_{\mathrm{fa}}\right)\right) \text { and } \sigma_{\mathrm{H}, \max }=\mathrm{B}\left(\sigma_{\mathrm{fr}}+\sigma_{\mathrm{fa}}\right) \\
& \text { with } \mathrm{A}=\sqrt{\frac{\left(1-v+v^{2}\right)}{3}} \text { and } \mathrm{B}=\frac{(1+v)}{3} .
\end{aligned}
$$

The equivalent maximum Crossland stress is provided by:

$$
\sigma_{\mathrm{C}, \max }=\sigma_{\mathrm{fr}}\left(\mathrm{A}+\alpha_{\mathrm{C}} \mathrm{B}\right)+\sigma_{\mathrm{fa}}\left(\left(\frac{1-\mathrm{R}_{\mathrm{fa}}}{2}\right) \cdot \mathrm{A}+\alpha_{\mathrm{C}} \mathrm{B}\right) \text {. }
$$

Considering the threshold crack nucleation condition (i.e., $\sigma_{\mathrm{C}, \max }=\tau_{\mathrm{d}}$ ), the following threshold contact stress condition can be defined:

$$
\sigma_{\mathrm{fr}_{-} \mathrm{C}}=2 \cdot \mathrm{q}_{\text {max }_{-} \mathrm{C}} \mathrm{f}(\mathrm{h}, \mathrm{k})=\frac{1}{\left(\mathrm{~A}+\alpha_{\mathrm{C}} \mathrm{B}\right)}\left(\tau_{\mathrm{d}}-\sigma_{\mathrm{fa}}\left(\left(\frac{1-\mathrm{R}_{\mathrm{fa}}}{2}\right) \cdot \mathrm{A}+\alpha_{\mathrm{C}} \mathrm{B}\right)\right) \text {. }
$$

For pre-stressed fretting conditions, the above expressions are simplified by using $\mathrm{R}_{\mathrm{fa}}=1$ and $\mathrm{h}=0$, so that $\mathrm{f}(\mathrm{h}, \mathrm{k})=1$. The plain fretting condition leads to following simplified expressions:

$$
\begin{aligned}
& \sqrt{\mathbf{J}_{2, \mathrm{a}}}=A \sigma_{\mathrm{fr}}=2 A \mathrm{q}_{\text {max }} \text { and } \sigma_{\mathrm{H}, \text { max }}=\mathrm{B} \sigma_{\mathrm{fr}}, \\
& \sigma_{\mathrm{C}, \max }=\sigma_{\mathrm{fr}}\left(\mathrm{A}+\alpha_{\mathrm{C}} \mathrm{B}\right)=2 \mathrm{q}_{\max }\left(\mathrm{A}+\alpha_{\mathrm{C}} \mathrm{B}\right)=2 \mathrm{q}_{0}\left(1-\mathrm{k}^{2}\right)^{1 / 2}\left(\mathrm{~A}+\alpha_{\mathrm{C}} \mathrm{B}\right),
\end{aligned}
$$

so that $\sigma_{f_{-}{ }_{-}}=2 \cdot q_{m_{x_{-}} C}=\frac{\tau_{d}}{\left(A+\alpha_{C} B\right)}$.

\section{DISCUSSION}

\subsection{Local stress analysis}

\subsubsection{Crack nucleation description using contact force parameters: $Q^{*}-P$ fretting map and $Q^{*}-\sigma_{\mathrm{fa}}$ fretting fatigue map}

A common approach to quantifying fretting cracking response consists in reporting the crack nucleation boundary in a tangential force - normal force diagram (i.e., Q*- P chart) [15] or using an equivalent tangential force - fatigue stress representation (i.e., $Q^{*}-\sigma_{\mathrm{fa}}$ fretting 
fatigue map) [21]. Such a mapping approach is very convenient for comparing, for a given contact geometry, the effect of normal force and synergic interactions between fretting and fatigue stressing or for evaluating the performance of bulk materials and palliatives such as shot-preened or surface coatings. Figure 9a shows that, for a given contact radius, the normal force tends to increase the $\mathrm{Q}_{\mathrm{CN}}^{*}$ condition whereas an increase in fatigue loading reduces the $\mathrm{Q}_{\mathrm{CN}}^{*}$ threshold (Fig. 9b). Comparison between cylinder various geometries is more complex. Figure 9a shows that, keeping the normal force constant, an increase in contact radius from $\mathrm{R}=20 \mathrm{~mm}$ to $\mathrm{R}=40 \mathrm{~mm}$, sharply increases the $\mathrm{Q}_{\mathrm{CN}}^{*}$ threshold. Indeed, applying a constant normal force, an increase in contact size reduces maximum contact pressure, contact stressing and therefore cracking risk. This tendency is confirmed in the $Q^{*}-\sigma_{\mathrm{fa}}$ fretting fatigue chart where, although similar maximum pressures are imposed, the tangential force threshold is lower for the smaller cylinder radius. However, the shift of the $\mathrm{Q}_{\mathrm{CN}}^{*}$ boundaries is smaller when the contact size is becoming very small (e.g. comparison between $\mathrm{R}=40$ and $\mathrm{R}=20 \mathrm{~mm}$ in Figure 9a). To interpret this tendency, it must be underlined that crack nucleation is controlled by maximum stress intensity but also by the material process volume over which this maximum stressing is operating. On the other hand, while an increase in contact radius reduces peak pressure, it also extends the influence of contact stress below the surface, and therefore increases the cracking process volume. This opposing tendency may explain the non-monotonic evolution of $\mathrm{Q}_{\mathrm{CN}}^{*}$ in the $\mathrm{Q}^{*}$ - $\mathrm{P}$ fretting chart. Finally, it can be said that if the $\mathrm{Q}^{*}$ - P and $\mathrm{Q}^{*}-\sigma_{\mathrm{fa}}$ contact force fretting charts are pertinent to compare surface treatment palliatives for a given contact geometry, they are not relevant to quantifying contact size or stress gradient effects according that they are not providing a global stress description of the fretting loading.

\subsubsection{Contact stress description: Introduction of the $\sigma_{\mathrm{fr}}-\mathbf{p}_{\max }$ fretting map and $\sigma_{\mathrm{fr}}-\sigma_{\mathrm{fa}}$ fretting fatigue mapping approach}

Depending on whether the fretting fatigue contact stressing can be represented by the $\sigma_{C}$ contact stress variable, equivalent $\sigma_{\mathrm{fr}}-\mathrm{p}_{\max }$ and $\sigma_{\mathrm{fr}}-\sigma_{\mathrm{fa}}$ charts can be introduced. These representations enable dissociation of the two tensile contributions induced at the trailing contact by the contact stressing, characterized by very severe stress gradients, and the homogeneous tensile fatigue loading. Besides, using these two representations, the various 
experimental crack nucleation conditions can be compared versus a single theoretical crack nucleation boundary $\left(\sigma_{\mathrm{fr} \_\mathrm{C}}\right)($ Eq. 41,38$)$ and plastic yield limit $\left(\sigma_{\mathrm{fr}} \mathrm{VM}_{\mathrm{V}}\right)(\mathrm{Eq} .28,24)$. In contrast to the previous $\mathrm{Q}^{*}-\sigma_{\mathrm{fa}}$ representation, the reverse-slip boundary is now related to a single master curve independent of cylinder radius (Eq. 25).

Assuming that local fatigue stress analysis can predict plain fretting crack nucleation risk, all of the experimental crack nucleation conditions can be expected to be aligned along a single the vertical boundary $\sigma_{\mathrm{fr}}=\sigma_{\mathrm{fr}} \mathrm{C}_{\mathrm{C}}($ Fig. 10a). By contrast, different quasi parallel evolutions according to the cylinder geometry were observed. Moreover, the experimental crack boundaries were not vertical, as predicted by the model, but displayed significant contact pressure dependencies, with a positive slope $\Delta \sigma_{\mathrm{fr}} / \Delta \mathrm{p}_{\max } \approx 0.4$. The experimental crack nucleation conditions were systematically above the theoretical Crossland prediction and sometimes exceeded the plastic yield limit. To interpret this evolution, we need to consider Neuber's theory [8] which shows that the crack nucleation process generated in a severe stress gradient configuration, such as those imposed by notched specimens or fretting contacts, is controlled by the maximum "hot spot" stress state but also by the process volume over which this maximum stressing condition is operating. The smaller the process volume (i.e., the higher the stress gradient), the higher the expected "hot spot" stress value to generate crack nucleation. Assuming a Hertzian contact description, it can be intuited that the effective process volume increases with contact size. Therefore, keeping the maximum contact pressure constant, an increase in contact size due to larger cylinder radius will reduce the $\sigma_{\text {fr }}$ cracking stress threshold. The pressure effect is more complex to interpret. Indeed, for a given cylinder radius, an increase in contact pressure by extending the contact size would be expected to reduce the $\sigma_{\text {fr }}$ stress threshold, whereas the contrary is in fact observed. To explain this tendency, it must be underlined that the higher the peak pressure for a given contact radius, the sharper the stress gradient generated in the sliding zone next to the contact border. The positive slope which characterizes the $\sigma_{\mathrm{fr}}-\mathrm{p}_{\max }$ evolution suggests that this stress-gradient sharpening effect compensates for the contact extension influence, so that the corresponding process volume is reduced and consequently the $\sigma_{\mathrm{fr}}$ fretting contact stress threshold increases with applied peak pressure.

Similar conclusions can be drawn from the $\sigma_{\mathrm{fr}}-\sigma_{\mathrm{fa}}$ fretting fatigue chart (Fig. 10b). Whereas similar contact pressures are imposed, the smaller $\mathrm{R}=40 \mathrm{~mm}$ radius configuration leads to 
larger threshold $\sigma_{\mathrm{fr}}$ values. Using a larger cylinder radius, the process volume enduring maximum stress is increased, and consequently threshold contact stress is reduced. It is interesting to note that the proposed $\sigma_{\mathrm{fr}}-\mathrm{p}_{\max }$ chart is equivalent to the $\mathrm{q}_{\max }-\mathrm{p}_{\max }$ representation proposed by Amargier et al. in [22] according that the $\sigma_{\mathrm{fr}}$ stress is directly proportional to the maximum interfacial shear value when $h=0$ (20). This correlation cannot be transposed for varying fatigue conditions (i.e., $h>0$ ). Significant fluctuations of the $f(h, k)$ factor can be observed depending on the $\mathrm{h}$ and $\mathrm{k}$ variables (19). This suggests that an equivalent $q_{\max }-\sigma_{\mathrm{fa}}$ fretting fatigue chart is not suitable for formalizing the fretting fatigue cracking process.

\section{Equivalent Haigh fretting fatigue chart}

As usually observed in the literature, the studied fretting fatigue conditions imply that both fretting $\left(\sigma_{\mathrm{fr}}\right)$ and fatigue $\left(\sigma_{\mathrm{fa}}\right)$ stresses are in phase and collinear. This allows an equivalent Haigh fretting fatigue representation to be considered where the crack nucleation boundary can be expressed as a function of a total stress amplitude and a total mean stress:

$$
\sigma_{\mathrm{a}}=\sigma_{\mathrm{fr}}+\frac{\sigma_{\mathrm{fa}}}{2}\left(1-\mathrm{R}_{\mathrm{fa}}\right) \text { and } \sigma_{\mathrm{m}}=\frac{\sigma_{\mathrm{fa}}}{2}\left(1+\mathrm{R}_{\mathrm{fa}}\right)
$$

Which, combined with (18), leads to

$$
\sigma_{\mathrm{a}}=2 \cdot \mathrm{q}_{0}\left(\left((1+\mathrm{h})^{2}-\mathrm{k}^{2}\right)^{1 / 2}-\mathrm{h}\right)+\frac{\sigma_{\mathrm{fa}}}{2}\left(1-\mathrm{R}_{\mathrm{fa}}\right) .
$$

Figure 11 compares the experimental $\left(\sigma_{\mathrm{a}}, \sigma_{\mathrm{m}}\right)$ results with the Goodman (M) and Gerber (G) approximations:

$$
\sigma_{\mathrm{a}_{-} M}=\sigma_{\mathrm{d}}\left(1-\frac{\sigma_{\mathrm{m}}}{\sigma_{\mathrm{u}}}\right) \text { and } \sigma_{\mathrm{a}_{-} \mathrm{G}}=\sigma_{\mathrm{d}}\left(1-\left(\frac{\sigma_{\mathrm{m}}}{\sigma_{\mathrm{u}}}\right)^{2}\right)
$$

As expected from Neuber's theory, the two uniaxial fatigue approximations lead to critical overestimations of cracking risk. Again, the largest difference with respect to the theoretical prediction is observed for the smallest contact radius, which also displays the highest stress gradient. This analysis underlines the fact that, despite the simplicity of the proposed uniaxial description involving the $\sigma_{\mathrm{fr}}-\mathrm{p}_{\max }$ and $\sigma_{\mathrm{fr}}-\sigma_{\mathrm{fa}}$ fretting charts or the equivalent $\sigma_{\mathrm{a}}-\sigma_{\mathrm{m}}$ Haigh representation, a local fatigue stress description is unable to capture the stress gradient effect and therefore is not suitable for predicting the fretting crack nucleation risk. 


\subsection{Non local Crossland multiaxial fatigue stress analysis}

Figure 7 confirms that, except at the local trailing contact border location, the fretting stress path is highly multiaxial and a function of both tangential and normal loads. A multiaxial fatigue description is therefore required. Crossland's fatigue criterion is here adopted. A local description is first considered, to quantify the gain in prediction obtained when non-local strategies are successively adopted (Fig. 12a).

\subsection{1 $\sqrt{J_{2, a}}-\sigma_{H, \max }$ "hot spot" local stress field description}

Crossland analysis of the different crack nucleation conditions was performed applying the formulations developed for the "hot-spot" contact stress conditions (Eq. 35 to 41). As expected from the above uni-axial stress description, the experimental data were highly dispersed and systematically above the material boundary (Fig. 12b). This local Crossland fatigue approach did not integrate the severe stress gradients operating next to the "hot spot" and therefore it could not provide relevant predictions. To quantify the stability of the prediction, the mean value and the square root variance of the equivalent Crossland stress obtained for the 16 test conditions were computed.

$$
\sigma_{\mathrm{C}, \mathrm{m}}=\frac{1}{\mathrm{~N}} \sum_{\mathrm{i}=1}^{\mathrm{N}} \sigma_{\mathrm{C}, \max }(\mathrm{i}) \text { and } \mathrm{V} \sigma_{\mathrm{C}}=\sqrt{\frac{\sum_{\mathrm{i}=1}^{\mathrm{N}}\left(\sigma_{\mathrm{C}, \max }(\mathrm{i})-\sigma_{\mathrm{C}, \mathrm{m}}\right)}{\mathrm{N}-1}}
$$

as well as the corresponding relative variable defined by:

$$
\% \mathrm{E} \sigma_{\mathrm{C}}=\left(\frac{\sigma_{\mathrm{C}, \mathrm{m}}-\tau_{\mathrm{d}}}{\tau_{\mathrm{d}}}\right) \times 100 \text { and } \% \mathrm{~V} \sigma_{\mathrm{C}}=\left(\frac{\mathrm{V} \sigma_{\mathrm{C}}}{\sigma_{\mathrm{C}, \mathrm{m}}}\right) \times 100 \text {. }
$$

$\% \mathrm{E} \sigma_{C}$ estimates the global error of prediction versus the theoretical material prediction, whereas $\% \mathrm{~V} \sigma_{\mathrm{C}}$ provides a relative estimation of dispersion. For the given local fatigue description, $\% \mathrm{E} \sigma_{\mathrm{C}}$ was $+36 \%$ and $\% \mathrm{~V} \sigma_{\mathrm{C}}$ was $16 \%$ which, corresponded to critical overestimation and large dispersion of the predictions.

This analysis demonstrated that, whatever the fatigue formulation, a local stress description fails to predict fretting cracking risk.

\subsection{Constant critical distance fatigue approach}

\subsubsection{Taylors's approximation}


Different strategies can be applied to provide non local fatigue descriptions. The most common approach consists in defining a length scale dimension over which the stress loading path is averaged before being transposed in fatigue analysis. An volume averaging strategy [4] or critical distance method [23, 24] can be considered to predict the fretting cracking process. These two approaches lead to equivalent predictions if the corresponding length scale values are correctly identified [21]. The present analysis used the critical distance method, which consists in defining the stress state at a certain distance below $(\ell)$ the contact "hotspot" (i.e., $x=-a, z=\ell$ ) (Fig. 12a). This stress loading path, which indirectly takes into account the stress gradient effect, is then transposed to the Crossland multiaxial fatigue analysis to estimate the relevant crack nucleation risk. A major difficulty of this method is to determine an optimum critical distance length. A first approach consists in applying a constant value, according to the microstructure but independent of contact size and related stress gradient conditions. The critical distance can be approximated using Taylors's theory [9], developed from notch fatigue specimens, where it is assumed to be equal to half the value of the long crack propagation length $b_{0}$. This threshold transition is expressed as a function of the fatigue $\sigma_{\mathrm{d}}$ limit and the long crack threshold $\Delta \mathrm{K}_{0}$ :

$\ell_{\mathrm{T}}=\frac{\mathrm{b}_{0}}{2} \approx \frac{1}{2 \pi}\left(\frac{\Delta \mathrm{K}_{0}}{\sigma_{\mathrm{d}}}\right)^{2} \approx 5 \mu \mathrm{m}$

This strategy previously applied par Araujo et al. in [24] is now considered for the given Crossland's fatigue analysis (Fig. 13a). As expected, the experimental results were closer to the material boundary and the dispersion was reduced. Substituting $\sigma_{\mathrm{C}, \max }$ by $\sigma_{\mathrm{C}}\left(-\mathrm{a}, \ell_{\mathrm{T}}\right)$ so called $\sigma_{\mathrm{C}}\left(\ell_{\mathrm{T}}\right)$ in equations (45) and (46) the statistical analysis led to $\% \mathrm{E} \sigma_{\mathrm{C}}\left(\ell_{\mathrm{T}}\right)=11 \%$ and $\% \mathrm{~V} \sigma_{\mathrm{C}}\left(\ell_{\mathrm{T}}\right)=12 \%$. The global predictions were less conservative but still dispersed. After this analysis, it could be concluded that Taylor's approximation tends to underestimate the effective critical distance that would center the predictions on the material boundary. An alternative strategy developed in [21] consists in identifying the critical distance directly from the fretting experiments. Hence, for each $i^{\text {th }}$ fretting and fretting fatigue test, an inverse iterative computation method was applied to estimate the corresponding critical distance $\ell_{\mathrm{C}}$ which satisfying the crack nucleation condition:

$$
\sigma_{\mathrm{C}}\left(\ell_{\mathrm{C}}\right)=\tau_{\mathrm{d}} \text {. }
$$


The different $\ell_{\mathrm{C}}$ values found for each test condition were determined and compiled in

Table II. The corresponding mean value $\ell_{\mathrm{C}, \mathrm{m}}$ and related square root variance were computed: $\ell_{\mathrm{C}, \mathrm{m}}=10.8 \pm 6 \mu \mathrm{m}$. This suggests that the best prediction is obtained if the critical distance is equal to the long crack transition (i.e. $\ell_{\mathrm{C}, \mathrm{m}} \approx \mathrm{b}_{0}$ ). However, if the global prediction was centered on the material boundary $\left(\% \mathrm{E} \sigma_{\mathrm{C}}\left(\ell_{\mathrm{C}, \mathrm{m}}\right)=1 \%\right)$, the dispersion is still very large $\left(\% \mathrm{~V} \sigma_{\mathrm{C}}\left(\ell_{\mathrm{C}, \mathrm{m}}\right)=10 \%\right)$. To interpret the difference with the Taylor's approximation it must be underlined that the Araujo et al. [24] analysis was done using critical plane fatigue base models whereas a stress invariant model is here considered. This confirms that different critical distance values need to be applied depending on the chosen multiaxial fatigue approach [26]. This aspect will be later discussed in section 4.3.4.

\subsection{Development of a "stress gradient" dependent critical distance approach}

A major limitation of the above critical distance description is that a constant length scale value variable is used. Our results suggest that, in addition to depending on the material microstructure (i.e., fatigue properties), the effective critical distance is also a function of the stress gradient condition operating in the crack nucleation process volume. Hence, a new approach, involving a variable critical distance parameter according to the stress gradient condition was considered. Figure 14a plots the evolution of the different $\ell_{\mathrm{C}}$ critical distance values as a function of the mean hydrostatic stress gradient value computed around the hotspot trailing contact border $\bar{\nabla} \sigma_{\mathrm{H}, \max }$. This hydrostatic stress gradient is averaged over a cubic volume with an edge size equivalent to the crack nucleation length [22]. In the present investigation, this averaged length scale also corresponds to the long crack transition $\mathrm{b}_{\mathrm{pth}} \approx \mathrm{b}_{0}$ and is very close to the grain size.

$\bar{\nabla} \sigma_{\mathrm{H}, \max }=\sqrt{\left(\frac{\Delta \sigma_{\mathrm{H}, \max }}{\Delta \mathrm{x}}\right)^{2}+\left(\frac{\Delta \sigma_{\mathrm{H}, \max }}{\Delta \mathrm{y}}\right)^{2}+\left(\frac{\Delta \sigma_{\mathrm{H}, \max }}{\Delta \mathrm{z}}\right)^{2}}$ with $\Delta \mathrm{x}=\Delta \mathrm{y}=\Delta \mathrm{z}=\mathrm{b}_{\mathrm{pth}}=10 \mu \mathrm{m}$

Figure 14a shows that both plain fretting and fretting fatigue results are following a single trend which shows an significant increase of the critical distance value with the applied hydrostatic stress gradient. The optimum critical distance is not constant but seems function of the stress gradient condition. An alternative strategy would be to consider the stress gradient of the equivalent Crossland stress itself. However, confirming previous Papadopoulos developments [25], it was shown that the plain hydrostatic stress parameter, 
which is easier to determine and more convenient to transpose for fatigue approach comparisons, is suitable [22].

\subsubsection{Linear approximation}

A linear correlation was first assumed to express the critical distance evolution (Fig. 14a). The following expression was considered:

$\ell_{\mathrm{C}, \mathrm{l}}=\mathrm{K}_{\mathrm{C}, \mathrm{l}}\left(\bar{\nabla} \sigma_{\mathrm{H}, \max }-\bar{\nabla} \sigma_{\mathrm{H}, \mathrm{res}}\right)$

with $\bar{\nabla} \sigma_{\mathrm{H}, \mathrm{res}}=4.9 \mathrm{MPa} / \mu \mathrm{m}$ and $\mathrm{K}_{\mathrm{C}, \mathrm{l}}=0.813 \mu \mathrm{m}^{2} / \mathrm{MPa}$.

Using this linear approximation, the corresponding Crossland analysis of both plain fretting and fretting fatigue tests are reported in the corresponding $\sqrt{\mathbf{J}_{2, \mathrm{a}}}\left(\ell_{\mathrm{C}, 1}\right)-\sigma_{\mathrm{H}, \max }\left(\ell_{\mathrm{C}, 1}\right)$ diagram (Fig. 14b). The correlation between the experimental values and the material boundary was improved. The mean prediction was centered next to the material boundary with $\% \mathrm{E} \sigma_{\mathrm{C}}\left(\ell_{\mathrm{C}, 1}\right)=-0.5 \%$, whereas the dispersion was now significantly reduced, with $\% \mathrm{~V} \sigma_{\mathrm{C}}\left(\ell_{\mathrm{C}, 1}\right)=5.4 \%$.

\subsection{2 "Staircase" threshold approximation}

The above linear approximation is simple and useful, but unable to provide a physical description of the critical distance / stress gradient correlation. For instance, it suggests that below a threshold $\bar{\nabla} \sigma_{\mathrm{H} \text {,res }}=4.9 \mathrm{MPa} / \mu \mathrm{m}$ stress gradient condition, the critical distance is zero so that a plain local fatigue description could be considered, which is not consistent with the actual experiments and other fatigue notch investigations. Besides, it predicts an infinite evolution of critical distance with the applied stress gradient, which is physically not admissible. To palliate such limitations, a discontinuous "staircase" description involving three different stress gradient domains was considered to describe the asymptotic evolution of $\ell_{\mathrm{C}}$ (Fig. 15a):

I: Low stress gradient condition: Below a threshold low $\bar{\nabla} \sigma_{\mathrm{H}(\mathrm{I})}$ stress gradient value estimated around $12 \mathrm{MPa} / \mu \mathrm{m}$ the critical distance is assumed to be constant and equivalent to Taylor's notch approximation: $\ell_{\mathrm{C}(\mathrm{I})} \approx \ell_{\mathrm{T}} \approx \mathrm{b}_{0} / 2 \approx 5 \mu \mathrm{m}$. 
II: Intermediate stress gradient condition: For medium stress gradient conditions $\left(\bar{\nabla} \sigma_{\mathrm{H}(\mathrm{I})}<\bar{\nabla} \sigma_{\mathrm{H}, \max }<\bar{\nabla} \sigma_{\mathrm{H}(\mathrm{II})}\right)$, the critical distance displays a linear evolution linking the two low (I) and high (III) stress gradient domains.

III: High stress gradient condition: Above a second stress gradient threshold $\bar{\nabla} \sigma_{\mathrm{H}(\mathrm{II})} \approx 20 \mathrm{MPa} / \mu \mathrm{m}$, the critical distance tends to stabilize around a constant dimension $\ell_{\mathrm{C}(\mathrm{III})} \approx 18 \mu \mathrm{m} \approx 2 \mathrm{~b}_{0}$.

This "staircase evolution" can be expressed using the following equation:

If $\bar{\nabla} \sigma_{\mathrm{H}, \max } \leq \bar{\nabla} \sigma_{\mathrm{H}(\mathrm{I})}$ then $\ell_{\mathrm{C}, \mathrm{sc}}=\ell_{\mathrm{C}(\mathrm{I})}$,

If $\bar{\nabla} \sigma_{\mathrm{H}(\mathrm{I})} \leq \bar{\nabla} \sigma_{\mathrm{H}, \max } \leq \bar{\nabla} \sigma_{\mathrm{H}(\mathrm{II})}$ then $\ell_{\mathrm{C}, \mathrm{sc}}=\mathrm{K}_{\mathrm{C}, \mathrm{sc}}\left(\bar{\nabla} \sigma_{\mathrm{H}, \max }-\bar{\nabla} \sigma_{\mathrm{H}(\mathrm{I})}\right)+\ell_{\mathrm{C}(\mathrm{I})}$

with $\mathrm{K}_{\mathrm{C}, \mathrm{sc}}=\left(\ell_{\mathrm{C}(\mathrm{III})}-\ell_{\mathrm{C}(\mathrm{I})}\right) /\left(\bar{\nabla} \sigma_{\mathrm{H}(\mathrm{II})}-\bar{\nabla} \sigma_{\mathrm{H}(\mathrm{I})}\right) \approx 1.86 \mu \mathrm{m}^{2} / \mathrm{MPa}$.

If $\bar{\nabla} \sigma_{\mathrm{H}, \max } \geq \bar{\nabla} \sigma_{\mathrm{H}(\mathrm{II})}$ then $\ell_{\mathrm{C}, \mathrm{sc}}=\ell_{\mathrm{C}(\mathrm{III})}$

The application of this staircase approximation provided very good and stable predictions (Fig. 15b). All the experimental results were aligned along the material boundary.

The mean prediction was equivalent to the shear fatigue limit $\left(\% \mathrm{E} \sigma_{\mathrm{C}}\left(\ell_{\mathrm{C}, \mathrm{sc}}\right)=-1 \%\right)$ whereas the dispersion was again reduced in comparison to the linear approximation, with $\% \mathrm{~V} \sigma_{\mathrm{C}}\left(\ell_{\mathrm{C}, \mathrm{sc}}\right)=4.2 \%$. The error in prediction, which was now below 5\%, was in fact equivalent to the dispersion of the experimental values of the crack nucleation identification. Hence, in addition to providing a very good prediction of fretting and fretting fatigue crack nucleation through a very large spectrum of fatigue stresses and contact stress gradient conditions, the proposed "staircase" formulation solved most of the restrictions induced by a plain linear approximation. It linked the low stress gradient conditions related to the common fatigue notch situations and provided a limited distance value for the very high stress gradient conditions.

\subsubsection{Simplified bilinear approximation}

The former "staircase" description requires a large quantity of experimental data to be established. An alternative low-cost strategy, consisting in calibrating the critical distance / stress gradient function using the two test conditions defining the extreme stress gradient conditions (i.e., bracketing all the studied stress gradient conditions) and a third test condition related to the intermediate stress gradient situation was introduced (Fig. 16a). These 3 "key" 
stress gradient situations (so-called lower, medium and upper stress gradient bounds) can be derived from a dedicated low-cost plain fretting experimental investigation. The present analysis found that the lower, medium and upper stress gradient bounds corresponded respectively to the PF6 $\left(\mathrm{R}=80 \mathrm{~mm}, \mathrm{p}_{\max }=600 \mathrm{MPa}\right), \mathrm{PF} 4\left(\mathrm{R}=40 \mathrm{~mm}, \mathrm{p}_{\max }=800 \mathrm{MPa}\right)$ and $\mathrm{PF} 2\left(\mathrm{R}=20 \mathrm{~mm}, \mathrm{p}_{\max }=1000 \mathrm{MPa}\right)$ fretting test (Fig. 3, Table II). Using these three reference conditions, the following bilinear formulation was introduced:

If $\bar{\nabla} \sigma_{\mathrm{H}, \mathrm{lb}} \leq \bar{\nabla} \sigma_{\mathrm{H}, \max } \leq \bar{\nabla} \sigma_{\mathrm{H}, \mathrm{mb}}$ then $\ell_{\mathrm{C}, \mathrm{bl}}=\mathrm{K}_{\mathrm{C}_{-} \mathrm{bl}(\mathrm{I})}\left(\bar{\nabla} \sigma_{\mathrm{H}, \max }-\bar{\nabla}_{\mathrm{H}, \mathrm{lb}}\right)+\ell_{\mathrm{C}, \mathrm{lb}}$

If $\bar{\nabla} \sigma_{\mathrm{H}, \mathrm{mb}} \leq \bar{\nabla} \sigma_{\mathrm{H}, \max } \leq \bar{\nabla} \sigma_{\mathrm{H}, \mathrm{up}}$ then $\ell_{\mathrm{C}, \mathrm{bl}}=\mathrm{K}_{\mathrm{C}_{-} \mathrm{bl}(\mathrm{II})}\left(\bar{\nabla} \sigma_{\mathrm{H}, \mathrm{max}}-\bar{\nabla} \sigma_{\mathrm{H}, \mathrm{mb}}\right)+\ell_{\mathrm{C}, \mathrm{mb}}$

where and $\mathrm{K}_{\mathrm{C}_{-} \mathrm{bl}(\mathrm{I})}=\frac{\ell_{\mathrm{mb}}-\ell_{\mathrm{lb}}}{\bar{\nabla} \sigma_{\mathrm{H}, \mathrm{mb}}-\bar{\nabla} \sigma_{\mathrm{H}, \mathrm{lb}}}$ and $\mathrm{K}_{\mathrm{C}_{-} \mathrm{bl}(\mathrm{II})}=\frac{\ell_{\mathrm{ub}}-\ell_{\mathrm{mb}}}{\bar{\nabla} \sigma_{\mathrm{H}, \mathrm{ub}}-\bar{\nabla} \sigma_{\mathrm{H}, \mathrm{mb}}}$

with $\ell_{\mathrm{lb}}=\ell_{\mathrm{C}(\mathrm{FS} 6)}, \quad \ell_{\mathrm{mb}}=\ell_{\mathrm{C}(\mathrm{FS} 4)}, \quad \ell_{\mathrm{ub}}=\ell_{\mathrm{C}(\mathrm{FS} 2)} \quad$ and $\quad \bar{\nabla} \sigma_{\mathrm{H}, \mathrm{lb}}=\bar{\nabla} \sigma_{\mathrm{H}, \max (\mathrm{FS} 6)}$, $\bar{\nabla} \sigma_{\mathrm{H}, \mathrm{mb}}=\bar{\nabla} \sigma_{\mathrm{H}, \max (\mathrm{FS} 4)}, \bar{\nabla} \sigma_{\mathrm{H}, \mathrm{ub}}=\bar{\nabla} \sigma_{\mathrm{H}, \max (\mathrm{FS} 2)}$.

Figure 16a confirms a rather good description of critical distance evolution using this simplified bi-linear approximation. Comparison with experimental results in the $\sqrt{\mathbf{J}_{2, \mathrm{a}}}\left(\ell_{\mathrm{C}, \mathrm{bl}}\right)-\sigma_{\mathrm{H}, \max }\left(\ell_{\mathrm{C}, \mathrm{bl}}\right)$ diagram (Fig. 16b) shows a very nice correlation with the material boundary. The mean prediction is close to the shear fatigue limit whereas the dispersion is just slightly higher than the reference "staircase" approximation $\left(\% \sigma_{\mathrm{C}}\left(\ell_{\mathrm{C}, \mathrm{bl}}\right)=\right.$ $\left.+4 \%, \% \mathrm{~V} \sigma_{\mathrm{C}}\left(\ell_{\mathrm{C}, \mathrm{bl}}\right)=5 \%\right)$. Smooth conservative predictions are obtained, which is a positive aspect for industrial applications. Like the linear approach, this formulation is restricted to the studied stress gradient domain (i.e., $\ell_{\mathrm{lb}} \leq \ell_{\mathrm{C}, \mathrm{bl}} \leq \ell_{\mathrm{ub}}$ ) and cannot be extended to lower or higher stress gradient domains. However, using only 3 adequate fretting test conditions bracketing the studied stress gradient range, reliable predictions can be achieved.

\subsubsection{Comparison with critical plane approaches}

The analysis suggests that the critical distance changes with the applied stress gradient conditions contradicting the Neuber's and Taylor's theories which assume a constant critical distance value. One explanation could be related to the chosen multiaxial fatigue approach. Indeed, the Crossland's stress invariants formulation is fast and very convenient for FEM fatigue analysis. However, Susmel and Taylor show that the fatigue stress invariant formulations are not suitable for theory of critical distance [26] and critical plane fatigue approaches must be preferred. To clarify this aspect, the given reverse identification strategy 
is applied for the McDiamid [27, 28] and MWCM [26] critical plane fatigue criteria. The corresponding equivalent stresses are expressed respectively by:

$\sigma_{\mathrm{McD}}=\left\{1-\left[\frac{\sigma_{\mathrm{n}, \mathrm{m}}\left(\mathrm{n}^{*}\right)}{\sigma_{\mathrm{u}} / 2}\right]\right\}^{-1 / 2} \tau_{\mathrm{a}}(\mathrm{n} *)+\alpha_{\mathrm{McD}} \cdot \sigma_{\mathrm{n}, \mathrm{a}}\left(\mathrm{n}^{*}\right)^{3 / 2}$

and

$\sigma_{\mathrm{MW}}=\tau_{\mathrm{a}}(\mathrm{n} *)+\alpha_{\mathrm{MW}} \cdot \frac{\sigma_{\mathrm{n}, \max }\left(\mathrm{n}^{*}\right)}{\tau_{\mathrm{a}}\left(\mathrm{n}^{*}\right)}$,

with $\alpha_{\mathrm{McD}}=\frac{\tau_{\mathrm{d}}-\sigma_{\mathrm{d}} / 2}{\left(\sigma_{\mathrm{d}} / 2\right)^{3 / 2}}, \alpha_{\mathrm{MW}}=\tau_{\mathrm{d}}-\frac{\sigma_{\mathrm{d}}}{2}$,

$\tau_{\mathrm{a}}\left(\mathrm{n}^{*}\right)$, the shear stress amplitude relative to the plane of maximum shear stress amplitude (i.e. $\left.\mathrm{n}^{*}: \max _{\mathrm{n}}\left(\tau_{\mathrm{a}}(\mathrm{n})\right)\right)$ and $\sigma_{\mathrm{n}, \mathrm{X}}\left(\mathrm{n}^{*}\right)$ the stress normal to the plane of maximum shear stress amplitude ( $X=a$ : amplitude value, $X=m$ : mean value, $X=m a x ;$ maximum value).

Like for the Crossland's analysis, the critical distance related to each fretting and fretting fatigue crack nucleation conditions are computed solving the following expressions:

$\sigma_{\mathrm{McD}}\left(\ell_{\mathrm{McD}}\right)=\tau_{\mathrm{d}}$ and $\sigma_{\mathrm{MW}}\left(\ell_{\mathrm{MW}}\right)=\tau_{\mathrm{d}}$

The obtained $\ell_{\mathrm{McD}}$ and $\ell_{\mathrm{MW}}$ values are compiled in table (II). The averaged values are respectively $\ell_{\mathrm{McD}, \mathrm{m}}=16.8 \pm 7.7 \mu \mathrm{m}$ and $\ell_{\mathrm{MW}, \mathrm{m}}=16.4 \pm 7.3 \mu \mathrm{m}$. The two critical plane approaches, based on an equivalent formalism, lead to similar mean critical distance values. Like for the Crossland analysis, these values are significantly larger than the Taylor's approximation and show significant dispersions. Figure 17 confirms that even applying critical plane fatigue approaches, a variable evolution of the critical distance versus the stress gradient condition must be considered. Again, asymptotic evolutions are observed which can be approximated using a equivalent staircase formulation. It is interesting to note that in the low stress gradient domain (I), the critical distance converged to the Taylor's prediction, whereas in the high stress gradient conditions (i.e., domain III), the critical distance stabilized at a longer threshold values (i.e. $\ell_{\mathrm{McD}(\mathrm{III})} \approx 25 \mu \mathrm{m}$ and $\ell_{\mathrm{MW}(\mathrm{III})} \approx 20 \mu \mathrm{m}$ ). Again, applying this staircase description, the predictions converges to the material boundary (i.e., $\left.\% \mathrm{E} \sigma_{\mathrm{MW}}\left(\ell_{\mathrm{MW}, \mathrm{sc}}\right) \approx \% \mathrm{E} \sigma_{\mathrm{McD}}\left(\ell_{\mathrm{McD}, \mathrm{sc}}\right) \leq 1 \%\right)$ with very low dispersions (i.e., $\% \mathrm{~V} \sigma_{\mathrm{MW}}\left(\ell_{\mathrm{MW}, \mathrm{sc}}\right)$ $\left.\approx \% \operatorname{V} \sigma_{\mathrm{McD}}\left(\ell_{\mathrm{McD}, \mathrm{sc}}\right) \leq 5 \%\right)$. Coupling the Crossland analysis the following approximation of the critical distance evolution can be derived:

If $\bar{\nabla} \sigma_{\mathrm{H}, \max } \leq \bar{\nabla} \sigma_{\mathrm{H}(\mathrm{I})} \approx 12 \mathrm{MPa} / \mu \mathrm{m}$ then $\ell_{\mathrm{C}} \approx \ell_{\mathrm{McD}} \approx \ell_{\mathrm{MW}} \approx \ell_{\mathrm{T}} \approx \mathrm{b}_{0} / 2$ 
If $\bar{\nabla} \sigma_{\mathrm{H}, \mathrm{max}} \geq \bar{\nabla} \sigma_{\mathrm{H}(\mathrm{III})} \approx 20 \mathrm{MPa} / \mu \mathrm{m}$ then $\ell_{\mathrm{C}} \approx \ell_{\mathrm{McD}} \approx \ell_{\mathrm{MW}} \approx 2$ to $2.5 \mathrm{~b}_{0}$

With linear evolutions in the intermediate stress gradient domain.

The convergence of multi-axial fatigue criteria is explained by noting that the largest critical distances remain smaller than $30 \mu \mathrm{m}$ which correspond to a $\ell$ /a ratio smaller than 0.06 . Figure 7 confirms that for such small subsurface distances, the fretting stress field is nearly uniaxial which obviously reduces the variation between multi-axial fatigue descriptions. Alternatively, the evolution of the critical distance with the stress gradient condition can be interpreted considering the following remarks:

- The stress gradient weigh function approach introduced by Papadopoulos [25] and coauthors suggests that the crack nucleation process is function of the stress gradient condition and therefore it cannot be restricted to a single physical length scale.

- The studied fretting stress gradient conditions are much more severe than the ones observed in conventional fatigue notch configurations. For such unusual high stress gradient conditions, it can be assumed a stress gradient influence on the critical distance parameter. Note that for the low stress gradient domain (I) the given results converge to the Taylor's approximation.

- Finally, the Taylor approach is established for a cracking failure situation linking both fatigue limit and crack arrest conditions. By contrast, the given analysis defines the crack nucleation condition as the activation of an incipient $10 \mu \mathrm{m}$ length micro-crack which can leads or not to a final failure. This difference in terms of crack nucleation definition can explain the divergence between the given conclusions and the constant critical distance description predicted by the Taylor's theory.

\section{CONCLUSIONS}

An extensive experimental study was performed to investigate the high cycle crack nucleation conditions induced by elastic plain fretting and fretting fatigue cylinder/plane contact for a large spectrum of contact pressure, fatigue stress, and stress gradient conditions. The following results were obtained:

- Explicit formulations of the critical stress path operating at the "hot-spot" trailing contact border are provided by coupling Mindlin and Mc Even formalisms. An equivalent explicit formulation of Crossland's multixial fatigue criterion is also derived. 
- Considering the quasi-unixial stress condition which is applied at the trailing contact border, useful $\sigma_{\mathrm{fr}}-\mathrm{p}_{\max }$ fretting map, contact stress / fatigue stress $\sigma_{\mathrm{fr}}-\sigma_{\mathrm{fa}}$ fretting fatigue chart and equivalent $\sigma_{\mathrm{a}}-\sigma_{\mathrm{m}}$ Haigh fretting fatigue representations were introduced. However, such local uniaxial description, which does not take into account the very severe contact stress gradients, critically overestimates the cracking risk.

- The application of the non-local critical distance approach shows that the Taylors's formalism slightly overestimates the crack nucleation risk. A reverse approach established from a Crossland's modeling of experimental plain fretting and fretting fatigue crack nucleation conditions leads to a mean critical distance value significantly larger than the prediction provided by the Taylor theory. Besides, large dispersions exceeding $10 \%$ were observed. This conclusion was confirmed applying both McDiarmid and MWCM critical plane fatigue formulations.

- Plotting the evolution of optimal critical distance versus the applied mean hydrostatic stress gradient imposed at the crack nucleation location shows that the critical distance is not constant but tends to increase asymptotically with stress gradient level. A basic "staircase" formulation is introduced to describe the critical distance evolution from low to high hydrostatic stress gradient situations. Using this simple description, the dispersion in prediction is reduced below 5\%, which corresponds to the experimental value of crack nucleation detection scattering.

The proposed variable critical distance approach appears to be an interesting strategy for predicting the incipient cracking phenomena generated in very severe stress gradient situations such as fretting contact. Deeper investigations are, however, required to transpose this "engineering" description to a more physical approach where both stress gradient and microstructure aspects could be correlated and formalized.

\section{REFERENCES}

[1] Hoeppner DW, Chandrasekaran V, Elliot CB, editors. Fretting fatigue: current technology and practices; ASTM STP 1367, American Society for Testing and Materials, 2000, ISBN 0-8031-2851-7.

[2] Waterhouse, R.B., Fretting Fatigue, Applied Science publishers, 1981.

[3] Hills DA, Nowell D. Mechanics of fretting fatigue, Dordrecht: Kluwer Academic Publishers, 1994. 
[4] Fouvry S, Kapsa Ph, Sidoroff F, Vincent L. Identification of the characteristic length scale for fatigue cracking in fretting contacts. J. Phys. IV France 1998; 8: 159-166.

[5] Araújo JA, Nowell D. Analysis of pad size effects in fretting fatigue using short crack arrest methodology, International Journal of Fatigue 1999;21:947-956.

[6] Kitagawa H, Takahashi S. Application of fracture mechanics to very small cracks or the cracks in the early stage. Philadelphia: American Society for Metals, 1976:627-630.

[7] Szolwinski M.P., Farris T.N. Mechanics of fretting crack formation. Wear 1996; 198: 93-107.

[8] Neuber H. Theory of notch stresses. Berlin: Springer; 1958.

[9] Taylor D. Analysis of fatigue failures in components using the theory of critical distances. Engng Fail Anal 2005;12:906-14.

[10] Galtier A., Ph. D thesis, ENSAM BORDEAUX, 8, 1993.

[11] Henaff G. HDR thesis, Université de Poitiers, 1997.

[12] Meriaux J., Fouvry S., Kubiak K.J., Deyber S. Characterization of crack nucleation in TA6V under fretting-fatigue loading using the potential drop technique, International Journal of Fatigue, 2010; 32 (10):1658-1668.

[13] Fellows L.J., Nowell D, Hills DA. On the initiation of fretting fatigue cracks. Wear 1997;205:120-9.

[14] Lee H., Mall S. Investigation into effects and interaction of various fretting fatigue variables under slip-controlled mode. Tribol Int 2006;39:1213-9.

[15] Proudhon H., Fouvry S., Buffière J.-Y. A fretting crack initiation prediction taking into account the surface roughness and the crack nucleation process volume. International Journal of Fatigue,2005; 27(5):569-579.

[16] Johnson KL. Contact Mechanics, Cambridge University Press, 1985.

[17] Mindlin RD, Deresciewicz H. Elastic sphere in contact under varying oblique forces. J Appl Mech 1953, 75:327-344.

[18] McEwen E. Stress in elastic cylinders in contact along a generatrix, Philosophical Magazine, 1949, 40, 454.

[19] Nowell D., Hills, D.A. Mechanics of fretting fatigue tests, Int. Jnl. Mech. Sci., 1987, 29, 5: $355-365$

[20] Crossland B. Effect of large hydrostatic pressures on the torsional fatigue strength of an alloy steel. Proceeding of the Inter. Conf. On Fatigue of Metals, Inst. of Mechanical Engineers, London, 1956, pp. 138-149. 
[21] Fouvry S., Kubiak K., Development of a fretting-fatigue mapping concept: The effect of material properties and surface treatments, Wear, 2009, 267, 2186-2199.

[22] Amargier R., Fouvry S., Chambon L., Schwob C., Poupon C., Stress gradient effect on crack initiation in fretting using a multiaxial fatigue framework, International Journal of Fatigue, 2010, 32 (12) : 1904-1912.

[23] Araújo JA, Nowell D. The effect of rapidly varying contact stress fields on fretting fatigue. International Journal of Fatigue 2002; 24 (7): 763-775.

[24] Araujo J.A., Susmel L., Taylor D., Ferro J.C.T., Mamiya E.N. On the prediction of high-cycle fretting fatigue strength: Theory of critical distances vs. hot-spot approach Engineering Fracture Mechanics, 2008; 75(7): 1763-1778.

[25] Papadopoulos IV. Invariant formulation of a gradient dependant multiaxial high-cycle fatigue criterion. Eng Fract Mech 1996; 55(4): 513-28.

[26] Susmel L., Taylor D., Can the conventional High-Cycle multiaxial fatigue criteria be reinterpreted in terms of the theory of critical distance ?, SDHM 2006; 2 (2):91-108.

[27] McDiarmid, D. L. A general criterion for high-cycle multiaxial fatigue failure. Fatigue Fract. Eng. Mater. Structs 1991; 14: 429-453.

[28] Fouvry S., Elleuch K., Simeon G., Prediction of crack initiation under partial slip fretting conditions, Journal of strain analysis, ImechE, 2002; 37(6):549-564.

\section{NOMENCLATURE}

\section{Material properties}

E Young's modulus

$v \quad$ Poisson's coefficient

$\sigma_{\mathrm{u}} \quad$ Ultimate tensile stress

$\sigma_{\mathrm{d}} \quad$ Traction - compression fatigue limit $\left(\mathrm{R} \sigma=\sigma_{\min } / \sigma_{\max }=-1,10^{7}\right.$ cycles $)$

$\sigma_{\mathrm{y}}=\sigma_{\mathrm{y} 0.2 \%} \quad$ Tensile yield stress $(0.2 \%)$

$\tau_{\mathrm{y}} \quad$ Shear yield stress

$\tau_{d} \quad$ Shear fatigue limite ( $R \tau=-1,10^{7}$ cycles)

$\Delta \mathrm{K}_{0} \quad$ Range of the threshold value stress intensity factor (Mode I, R $\sigma=-1$ )

\section{Contact loadings \& Crack parameters}

$\mathrm{P} \quad$ Linear normal force

Q Fretting linear tangential force

Q* Fretting linear tangential force amplitude

$\mathrm{Q}_{\mathrm{CN}}^{*} \quad$ Fretting linear tangential force amplitude related to the crack nucleation condition $\left(b_{p} \geq b_{p t h}=10 \mu \mathrm{m}\right)$

$\mathrm{R} \quad$ Radius of the cylinder pad

$\delta \quad$ Fretting displacement

$\delta^{*} \quad$ Fretting displacement amplitude 
$\mu=\mu_{t} \quad$ Coefficient of friction (gross slip transition)

a Hertzian contact radius

c Radius of the stick zone

e Eccentricity of the stick zone induced by the fatigue strain

$\mathrm{k}=\mathrm{c} / \mathrm{a} \quad$ Stick ratio

$\mathrm{h}=\mathrm{e} / \mathrm{a} \quad$ Eccentricity ratio

$\mathrm{p}_{\max }=\mathrm{p}_{0} \quad$ Hertzian maximum peak pressure

$\mathrm{q}_{\max } \quad$ Maximum interfacial shear stress at $\mathrm{x}=-\mathrm{c}+\mathrm{e}$

$\mathrm{q}_{0}=\mu \mathrm{p}_{0} \quad$ Maximum interfacial shear stress at the gross slip transition $\left(\mathrm{Q}^{*}=\mu \mathrm{P}, \mathrm{x}=0\right)$

$b_{p} \quad$ Projected crack length (to the normal of the surface)

$\mathrm{b}_{\mathrm{p}, \max } \quad$ Maximum projected crack length

$\mathrm{b}_{\text {pth }} \quad$ Threshold crack nucleation projected crack length $(10 \mu \mathrm{m})$

\section{Stress \& critical distance parameters}

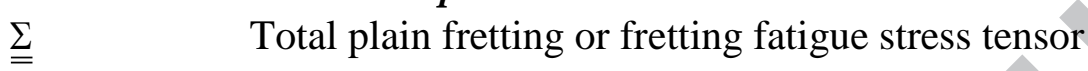

$\sum_{\mathrm{fr}} \quad$ Fretting stress tensor

$\sum_{\mathrm{fa}} \quad$ Fatigue stress tensor

$\sigma_{\mathrm{fa}}=\sigma_{\mathrm{fa}, \max }$ Maximum fatigue stress

$\sigma_{\mathrm{fa}, \min } \quad$ Minimum fatigue stress

$\mathrm{R}_{\mathrm{fa}} \quad$ Fatigue stress ratio $\left(\sigma_{\mathrm{fa}, \min } / \sigma_{\mathrm{fa}}\right)$

$\sigma_{\mathrm{fr}} \quad$ Maximum contact fretting stress imposed at the trailing contact border $\left(\mathrm{R}_{\mathrm{fr}}=-1\right)$

$\mathrm{T}_{\max } \quad$ Tresca shear stress

$\sigma_{\mathrm{VM}} \quad$ Equivalent Von Mises stress

$\sqrt{\mathrm{J}_{2, \mathrm{a}}} \quad$ Square root of the maximum amplitude of the second stress invariant

$\sigma_{\mathrm{H}} \quad$ Hydrostatic stress,

$\sigma_{\mathrm{H}, \max } \quad$ Maximum hydrostatic stress,

$\bar{\nabla} \sigma_{\mathrm{H}, \max } \quad$ Maximum hydrostatic stress gradient averaged over a cubic volume $\left(\mathrm{b}_{\mathrm{pth}}\right)$

$\sigma_{\mathrm{C}} \quad$ Crossland equivalent stress

$\sigma_{\mathrm{McD}} \quad$ McDiarmid equivalent stress

$\sigma_{\text {MW }} \quad$ MWCM equivalent stress

$\sigma_{\mathrm{a}} \quad$ Total amplitude stress (Haigh's analysis)

$\sigma_{\mathrm{m}} \quad$ Total mean stress (Haigh's analysis)

$\ell \quad$ Critical distance from the "hot spot" stress where the fatigue analysis is performed (i.e. $\mathrm{x}=-\mathrm{a}, \mathrm{z}=\ell$ )

$\ell_{\mathrm{T}} \quad$ Taylor's estimation of $\ell$

$\ell_{\mathrm{C}} \quad$ Crossland's reverse identification of

$\ell_{\mathrm{McD}} \quad$ McDiarmid's reverse identification of $\ell$

$\ell_{\text {MW }}$ MWCM's reverse identification of $\ell$ 
1

\section{Subscripts}

$-\mathrm{T}$

VM

- RS

-C

,a

, max

,m

, 1

,sc

,bl
Tresca shear yield limit

Von Mises yield limit

Reverse slip limit $(\mathrm{h}+\mathrm{k}=1)$

Crossland's crack nucleation limit

Amplitude value

Maximum value

Mean value

Linear approximation of $\ell=\mathrm{f}\left(\bar{\nabla} \sigma_{\mathrm{H}, \max }\right)$

Staircase approximation of $\ell=\mathrm{f}\left(\bar{\nabla} \sigma_{\mathrm{H}, \max }\right)$

Bilinear approximation of $\ell=\mathrm{f}\left(\bar{\nabla} \sigma_{\mathrm{H}, \max }\right)$ 


\section{FIGURES}

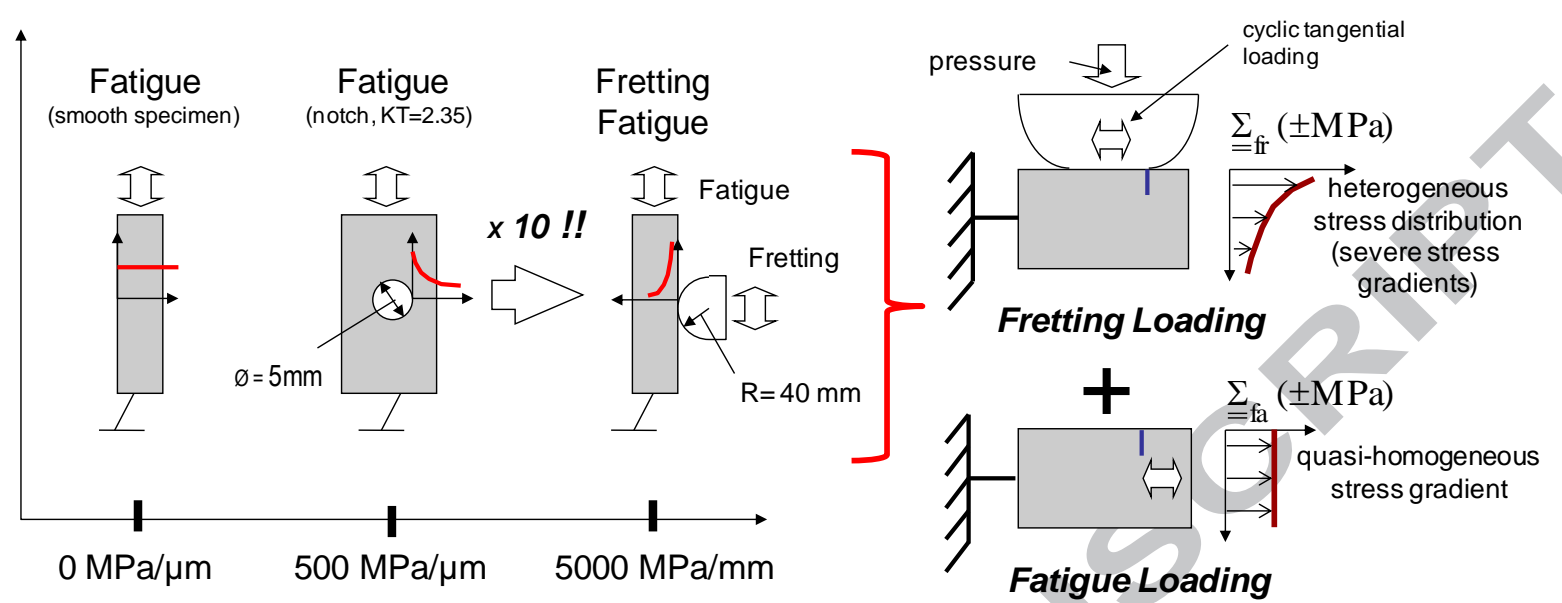

maximum gradient of the hydrostatic stress $\nabla \sigma_{\mathrm{H}, \max }$

Fig. 1 : Illustration of the very severe stress gradient conditions induced by fretting fatigue.
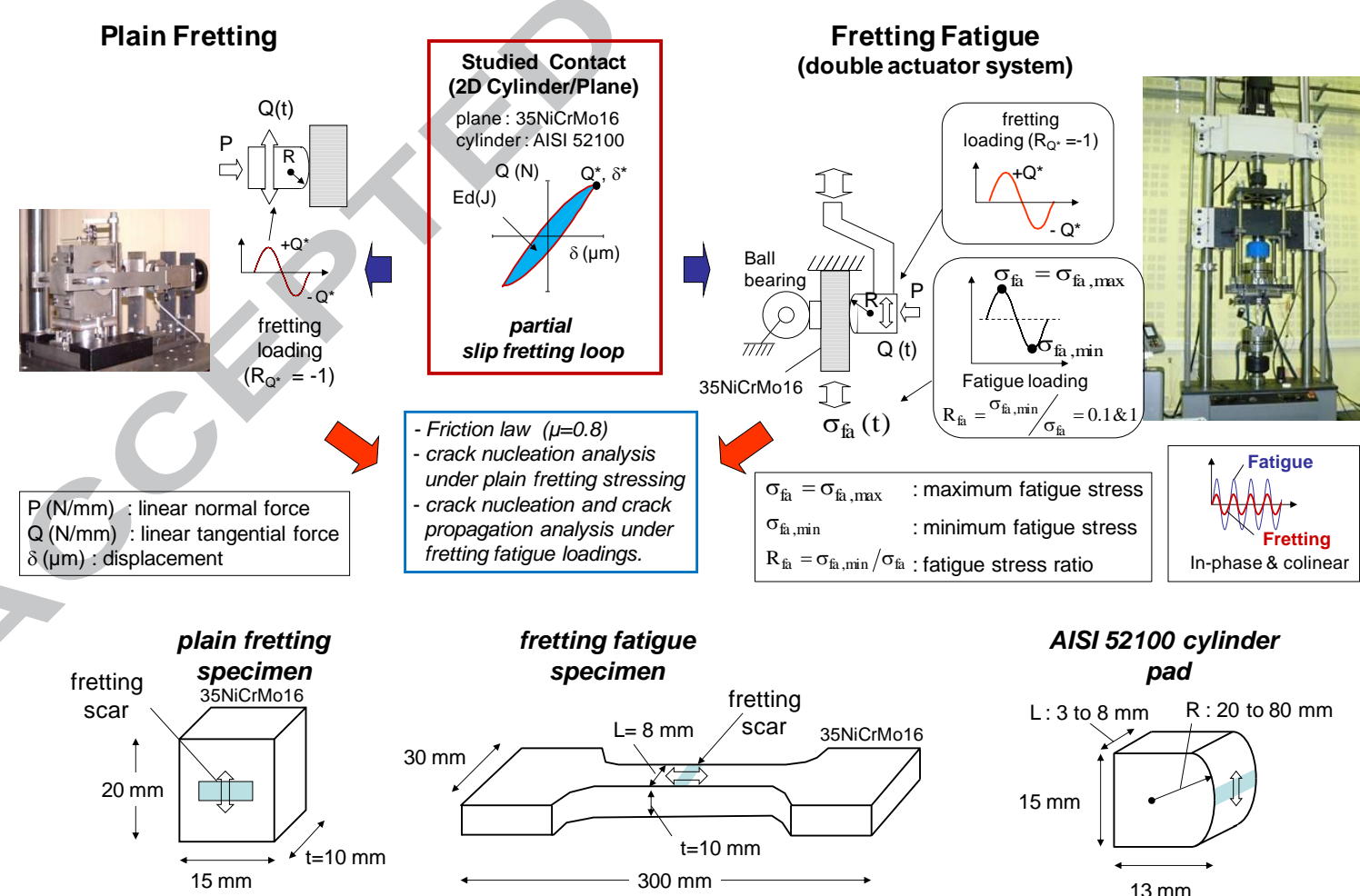

\section{AISI 52100 cylinder pad}

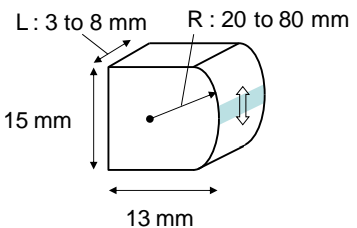

Fig. 2 : Experimental strategy based on combined plain fretting and fretting fatigue analysis involving similar contact configurations (schematics of the specimen geometries (Table II)). 


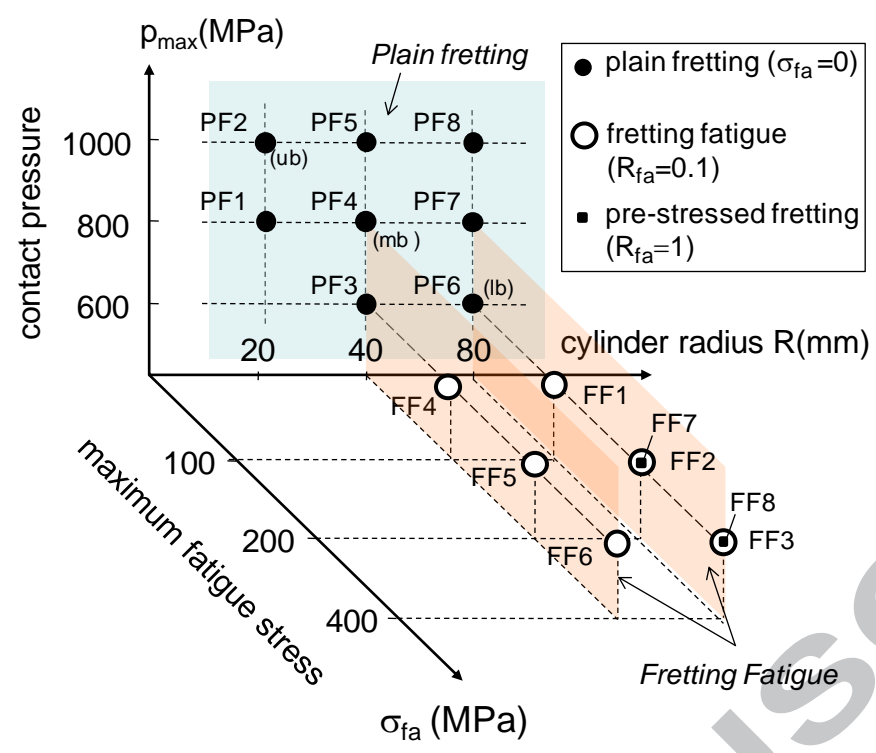

Fig. 3: Illustration of the matrix of tests developed in this fretting fatigue investigation; (ub), (mb), (lb) : respectively, upper, medium and lower stress gradient bounds conditions.

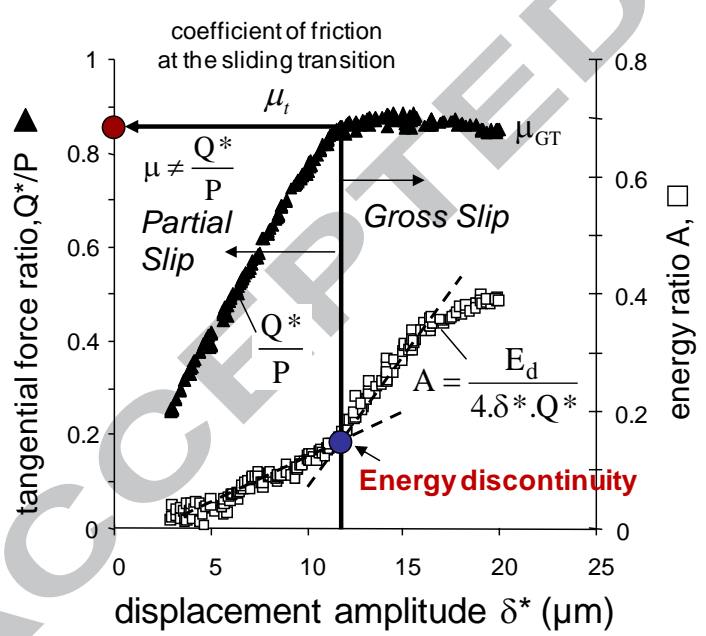

(a)

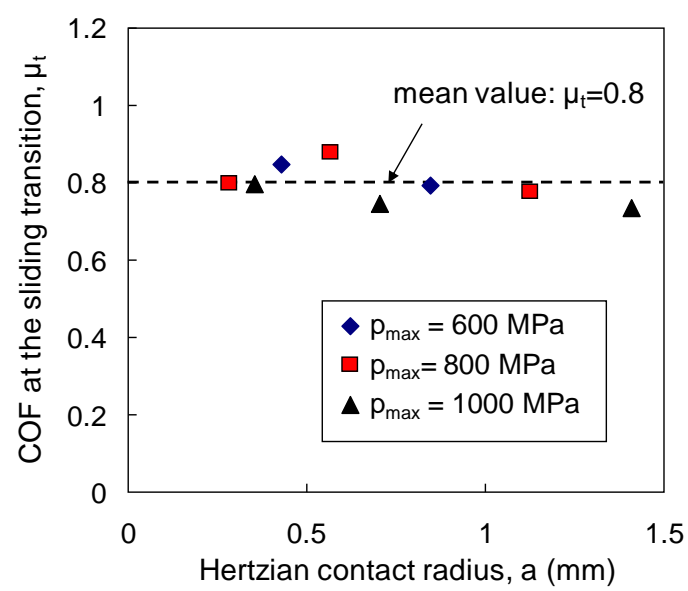

(b)

Fig. 4: Analysis of the coefficient of friction (COF) using plain fretting experiments: (a) Variable displacement method; (b) Evolution of the coefficient of friction at the sliding transition as a function of contact radius and maximum Hertzian pressure. 


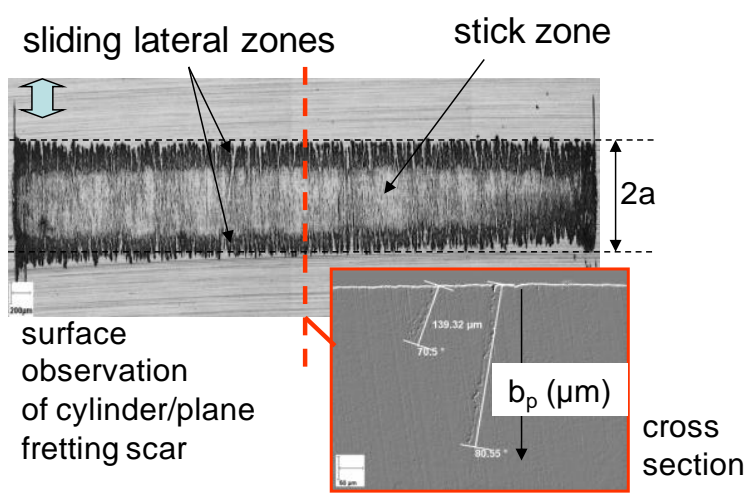

(a)

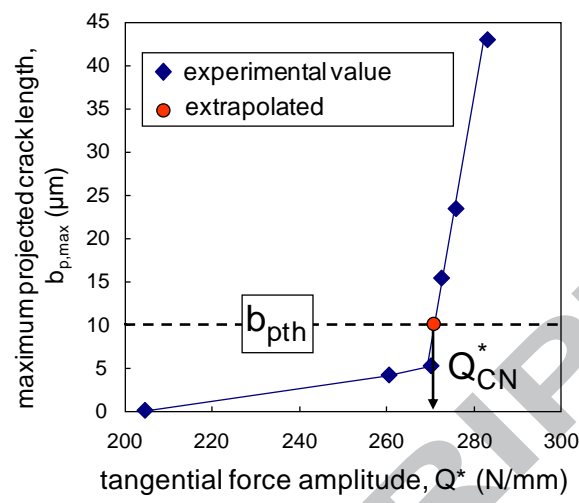

(b)

Fig. 5: Fretting crack examination: (a) Illustration of the destructive methodology; (b) Identification of the crack nucleation condition for a given fretting fatigue condition (PF3 test condition).

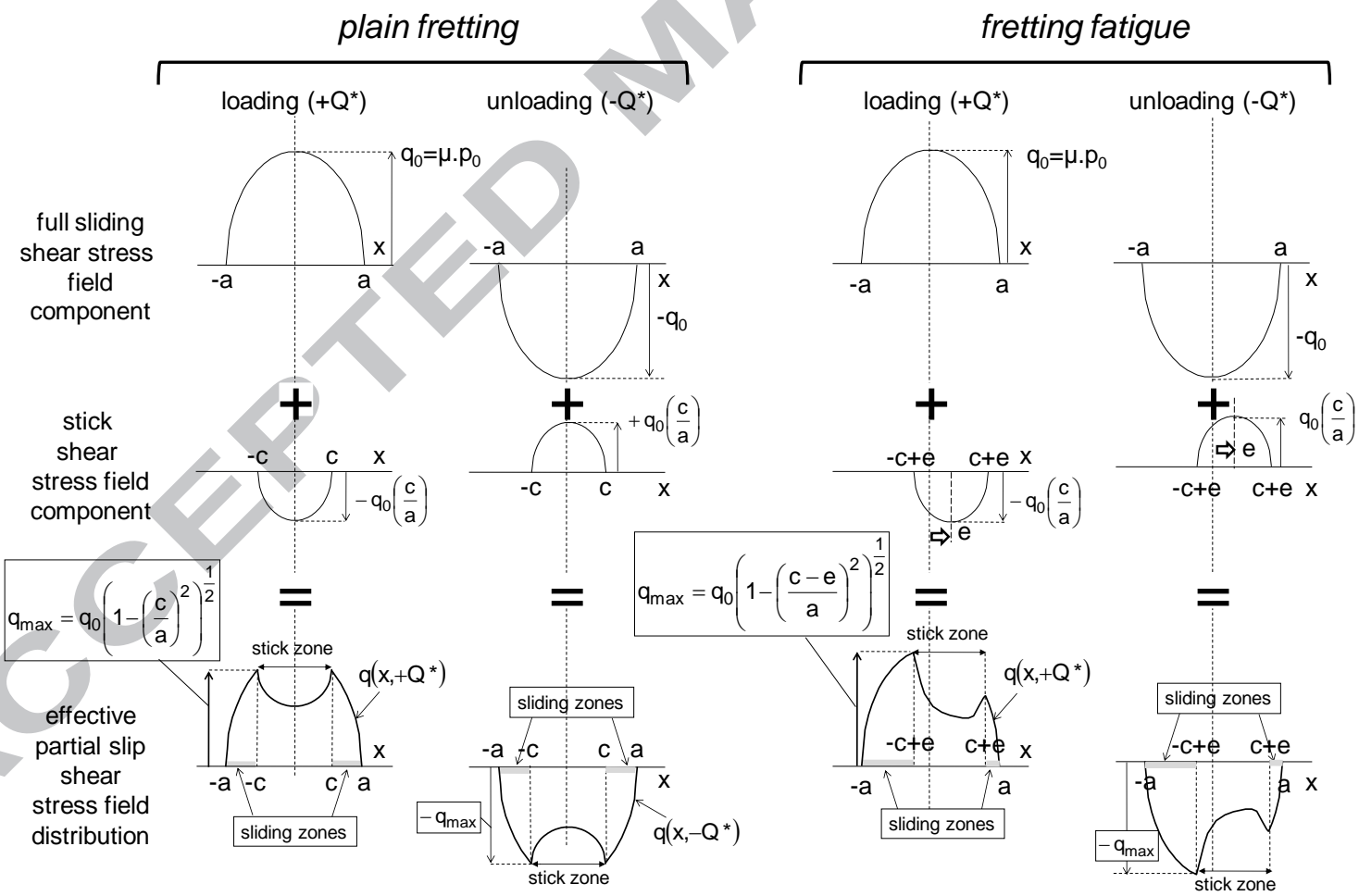

Fig. 6 : Illustration of Mindlin's surface shear distributions generated in partial slip cylinder/plane contact under plain fretting and fretting fatigue loading conditions. 


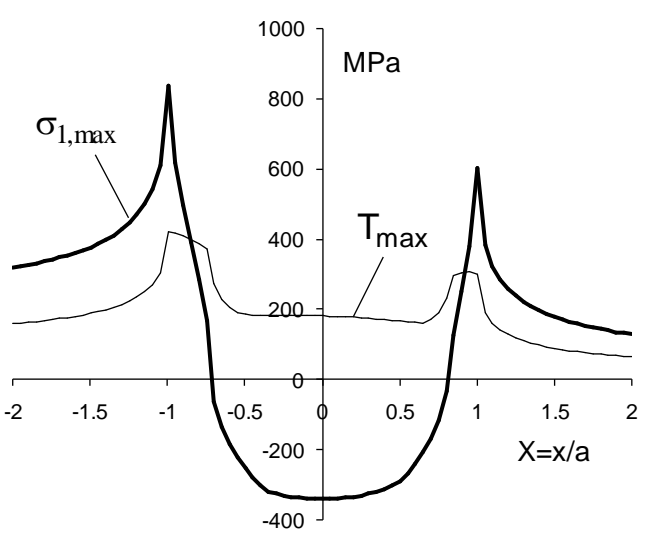

(a)

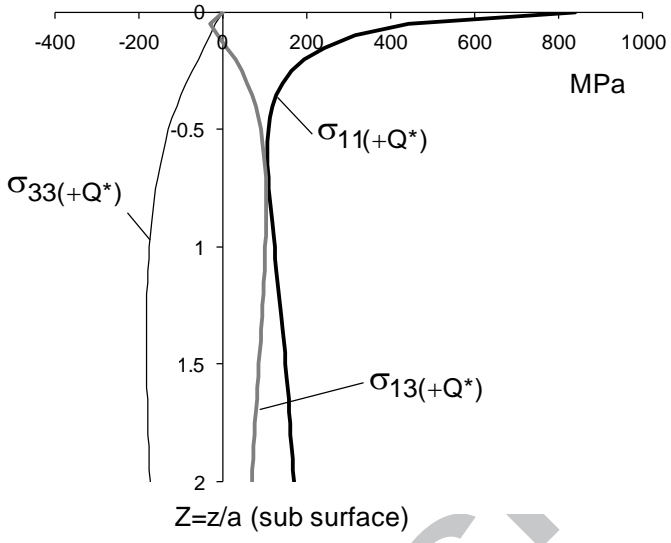

(b)

Fig. 7 : Total stress field analysis $(\underline{\underline{\Sigma}})$ of a representative fretting fatigue test condition (FF

2, Table II): (a) Surface maximum principal stress and Tresca shear generated during the fretting fatigue cycle; (b): Subsurface stress distributions along the $\mathrm{z}$ axis at the trailing contact border $(\mathrm{x}=-\mathrm{a})$ at the maximum loading stage $\left(+Q^{*}, \sigma_{\mathrm{fa}}, \underline{\underline{\Sigma}}_{\max }\right)$.

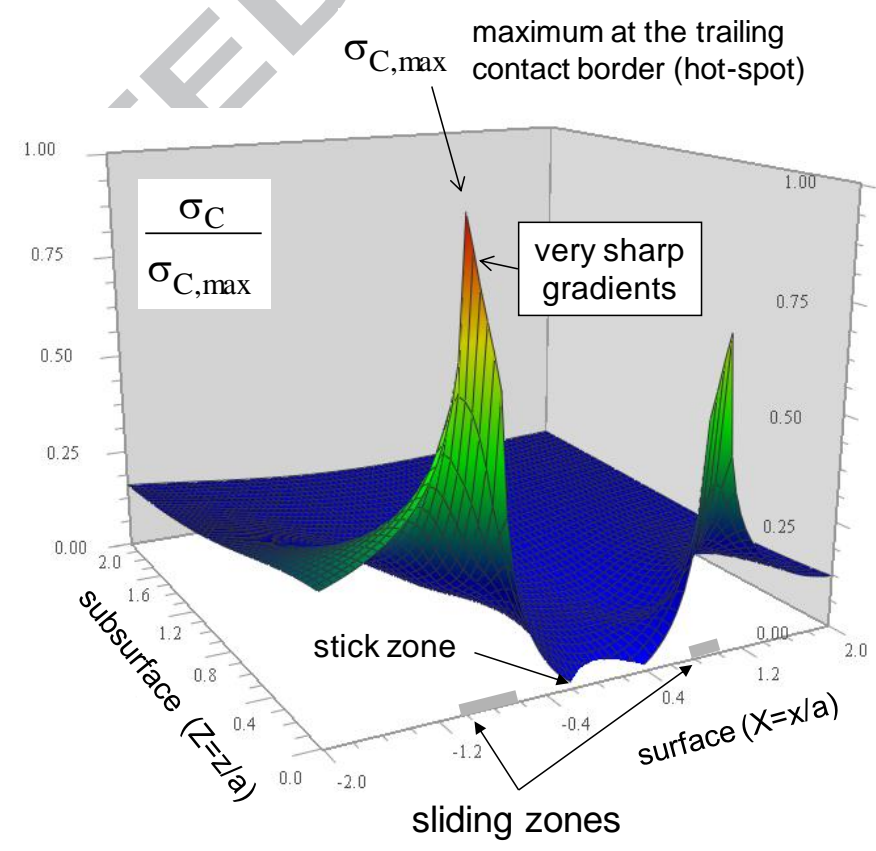

Fig. 8 : Subsurface distribution of the Crossland criterion computed for a representative crack nucleation fretting fatigue condition (Table II, FF2 condition, $\sigma_{\mathrm{C}, \max }=476 \mathrm{MPa}$ ). 


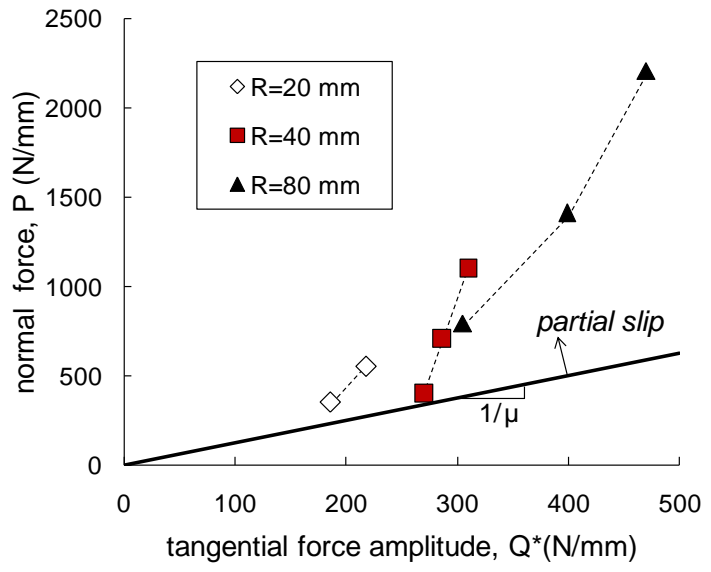

(a)

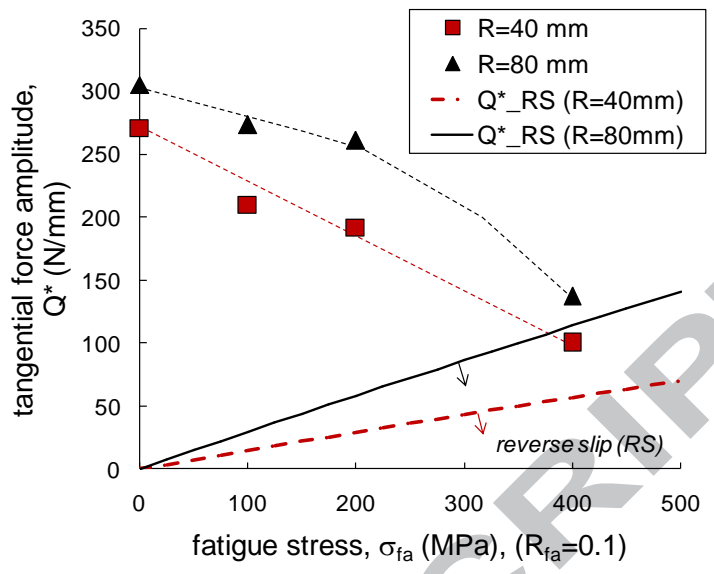

(b)

Fig. 9: " $Q *$ *"contact force representation of the crack nucleation conditions (Table II): (a) Q*- $\mathrm{P}$ fretting chart; (b) $\mathrm{Q}^{*}-\sigma_{\mathrm{fa}}$ fretting fatigue map $\left(\mathrm{p}_{\max }=600 \mathrm{MPa}\right)$.

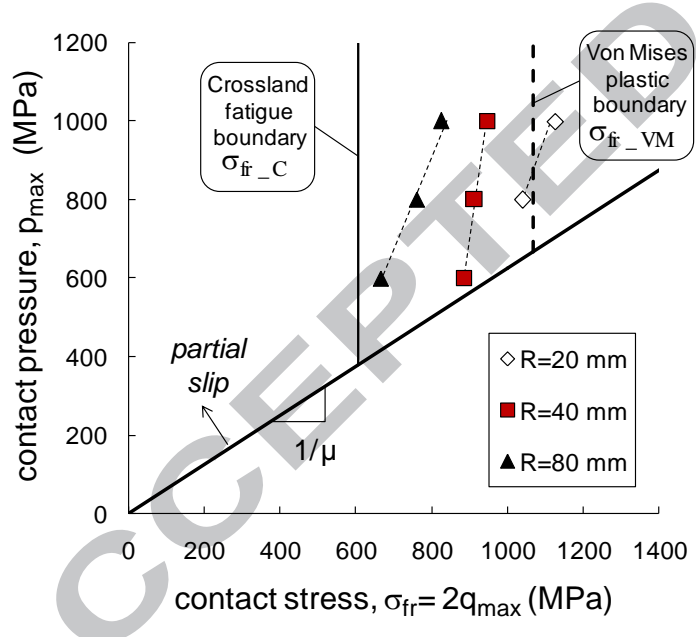

(a)

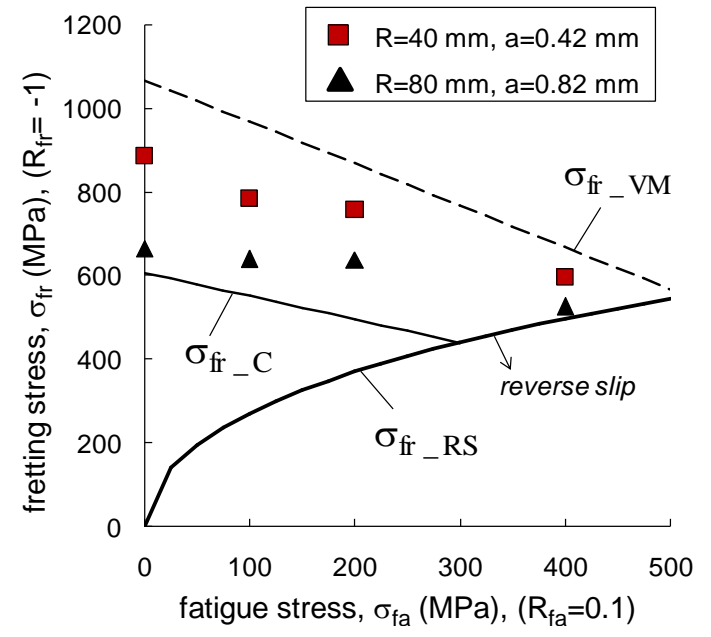

(b)

Fig. 10: " $\sigma_{\mathrm{fr}}$ " contact stress representation of the crack nucleation conditions (Table II ):

(a) $\sigma_{\mathrm{fr}}-\mathrm{p}_{\max }$ fretting chart; (b) $\sigma_{\mathrm{fr}}-\sigma_{\mathrm{fa}}$ fretting fatigue chart $\left(\mathrm{p}_{\max }=600 \mathrm{MPa}\right)$. 


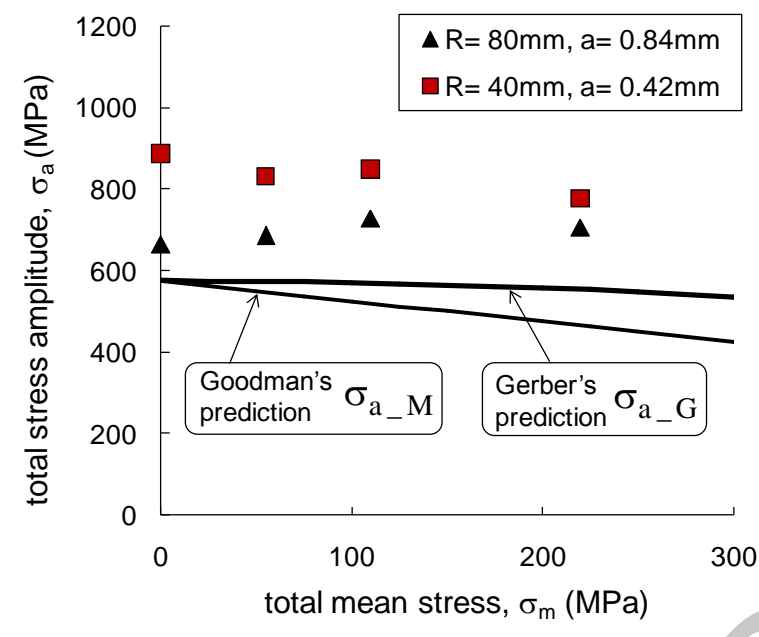

Fig. 11: Illustration of the equivalent "Fretting Fatigue Haigh's" diagram.

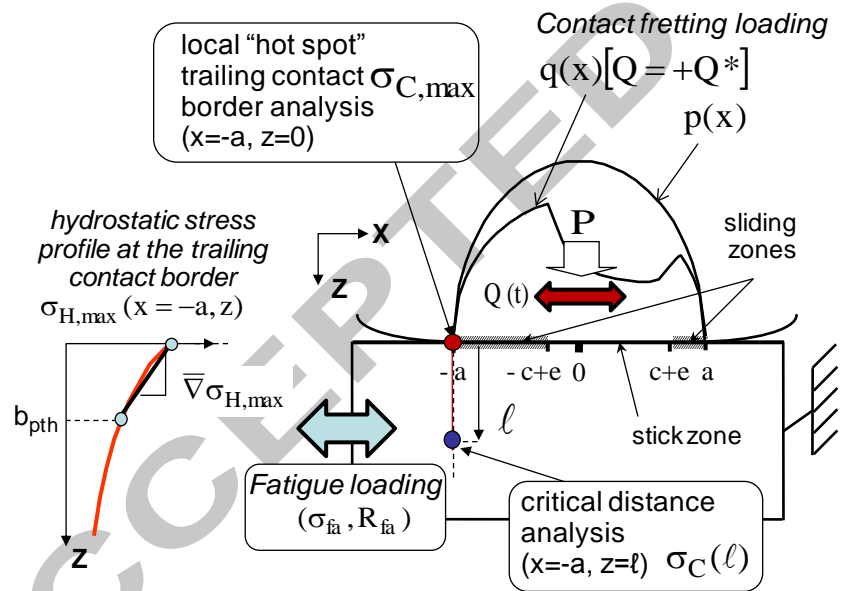

(a)

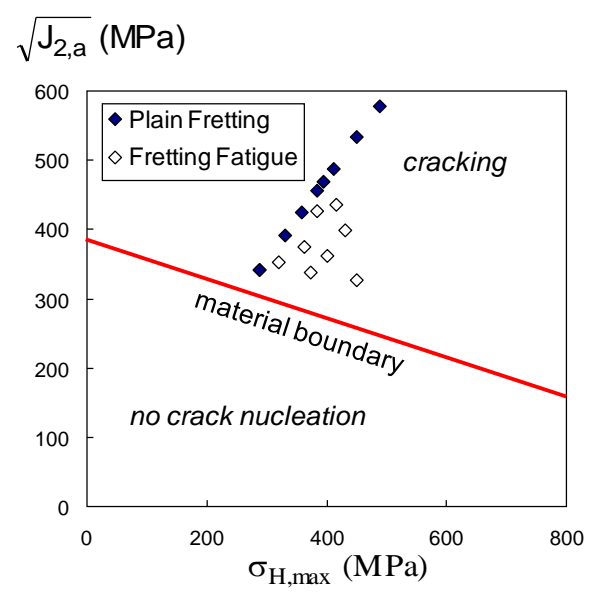

(b)

Fig. 12 (a) Illustration of local "hot-spot" and non-local critical distance approach transposed to fretting fatigue crack analysis; (b) $\sqrt{\mathrm{J}_{2, \mathrm{a}}}-\sigma_{\mathrm{H} \text {,max }}$ " hot spot" stress analysis of the plain fretting and fretting fatigue experiments (Table II). 


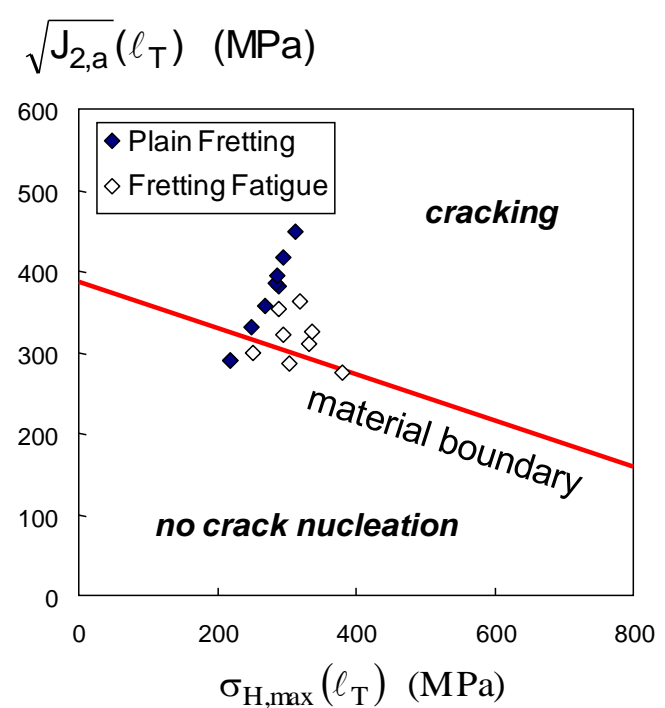

(a)

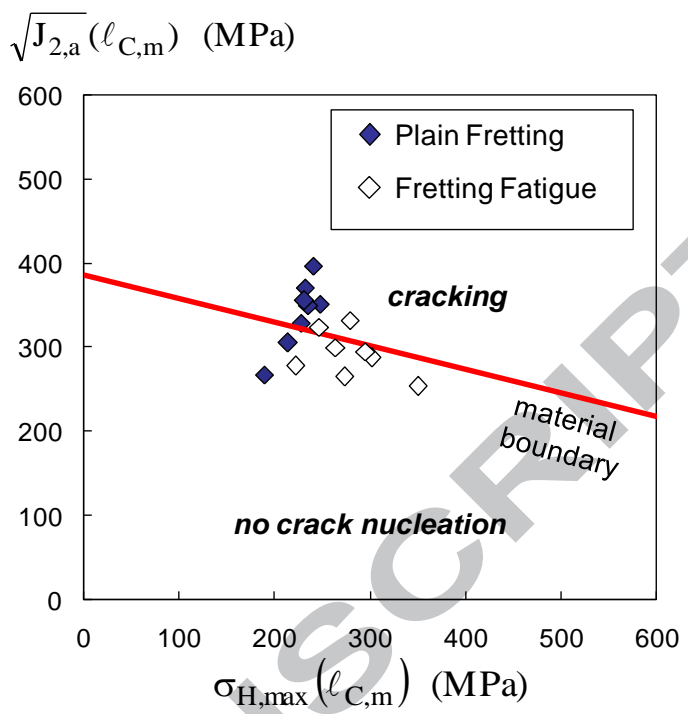

(b)

Fig. 13 : Application of the Critical distance approach (a) Taylor's approximation $\left(\ell_{\mathrm{T}}=\mathrm{b}_{0} / 2=5 \mu \mathrm{m}\right)$; (b) Reverse Fretting calibration $\left(\ell_{\mathrm{C}, \mathrm{m}}=10.8 \mu \mathrm{m} \approx \mathrm{b}_{0}\right)$.

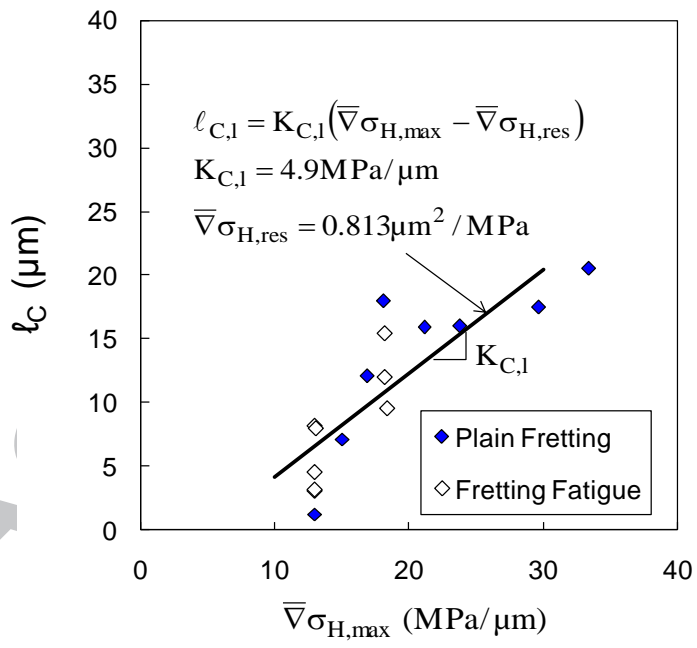

(a)

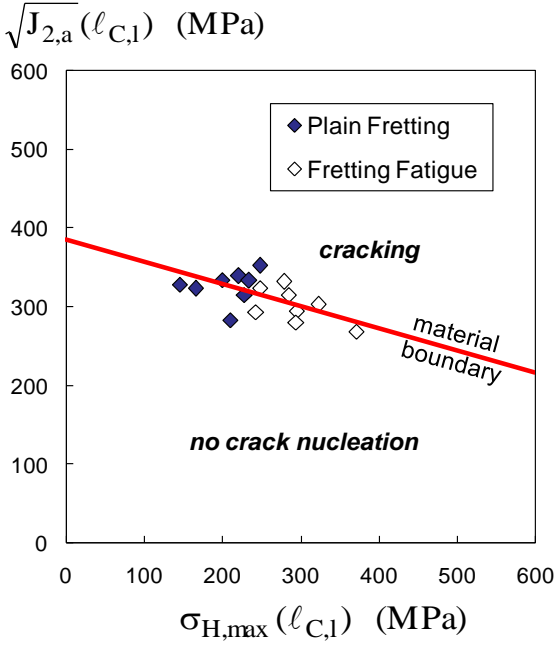

(b)

Fig. 14 : (a) Evolution of the critical distance extracted from the reverse Crossland analysis of fretting tests as a function of the gradient of the hydrostatic stress (identification of a linear approximation) (Table II); (b) Application of the linear approximation of the critical distance evolution versus the hydrostatic stress gradient. 


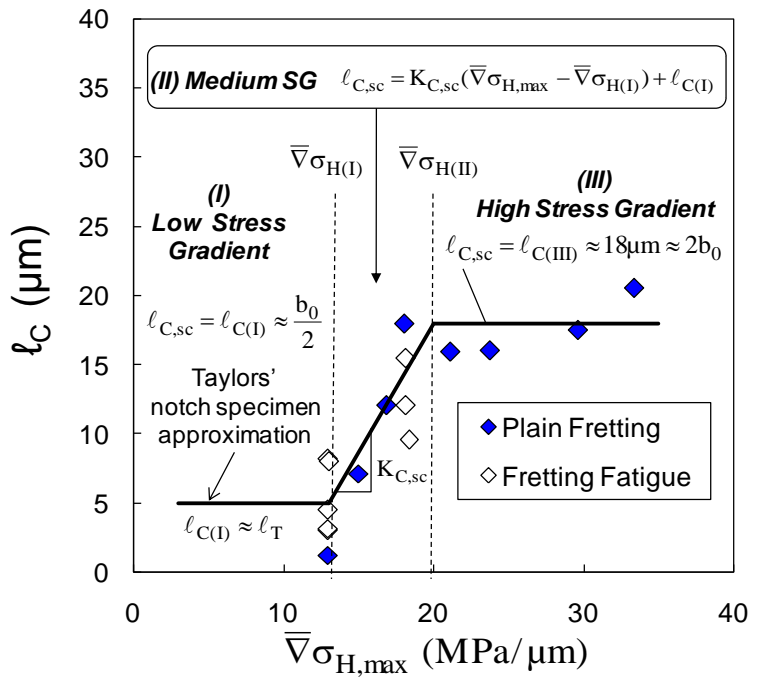

(a)

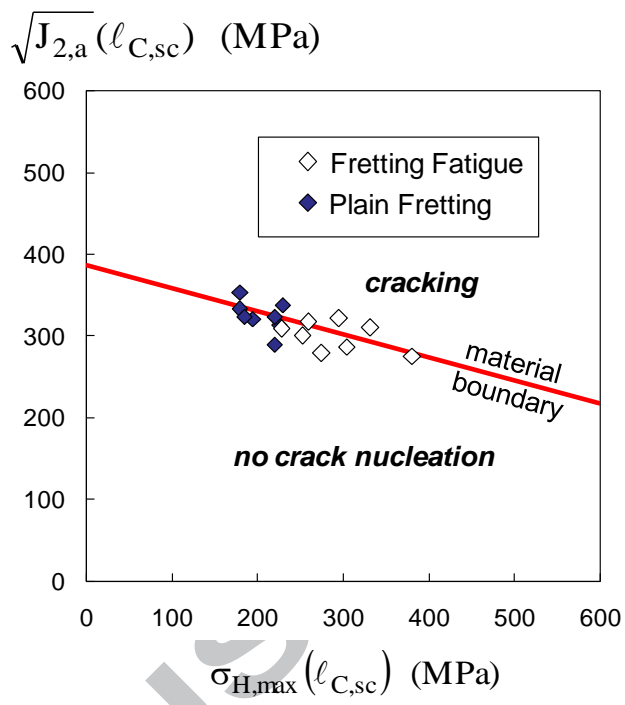

(b)

Fig. 15: Application of the "staircase' critical distance description: (a) Formulation of the staircase $\ell_{\mathrm{C}}^{\mathrm{sc}}$ variable as a function of the hydrostatic stress gradient; (b) Application of the "staircase" formulation to characterize the crack nucleation response.

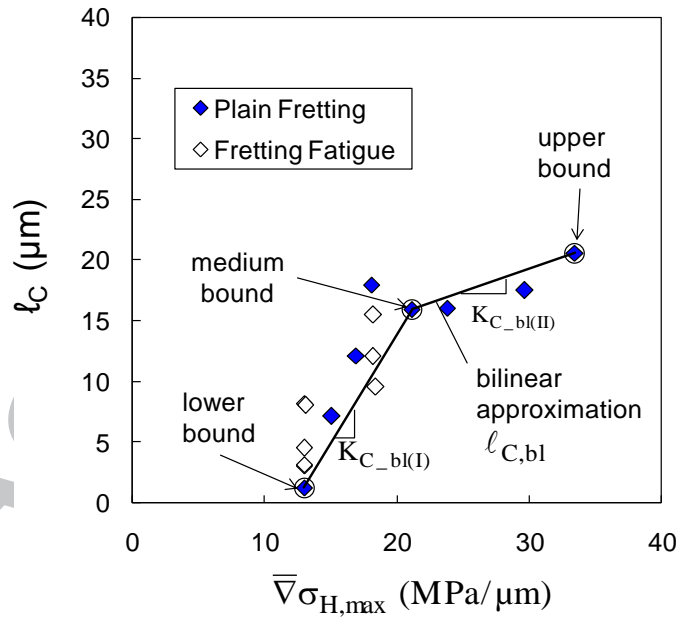

(a)

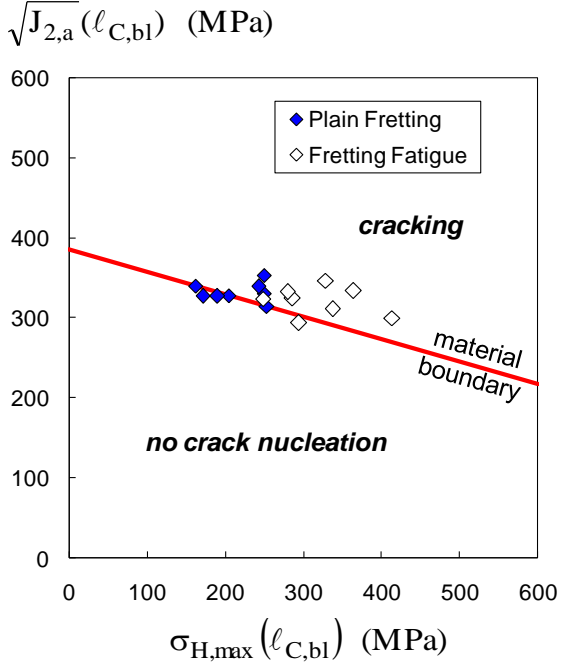

(b)

Fig. 16: Application of the simplified bilinear approximation of the critical distance evolution with the applied hydrostatic stress gradient: (a) Formulation of $\ell_{\mathrm{C}, \mathrm{bl}}$ bilinear approximation from plain fretting experiments, (b) Application of the bilinear approximation to predict plain fretting and fretting fatigue crack nucleation results. 


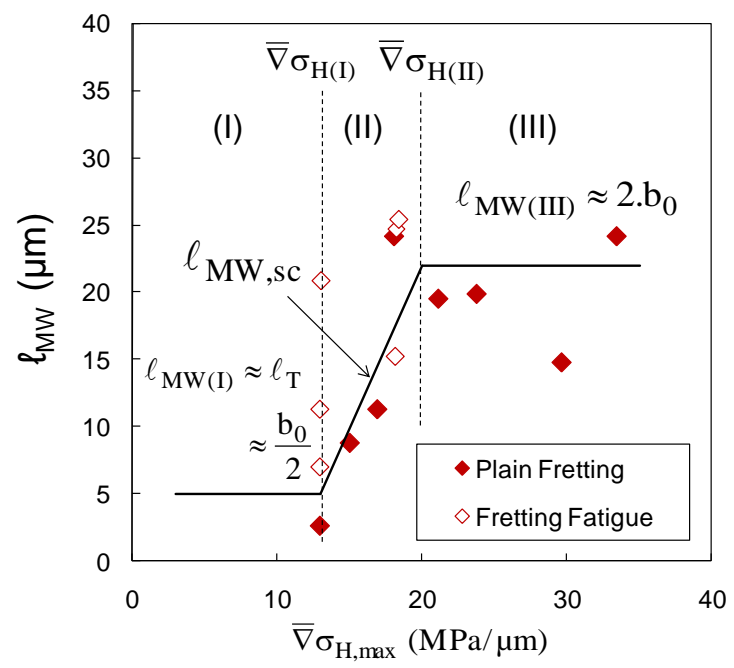

(a)

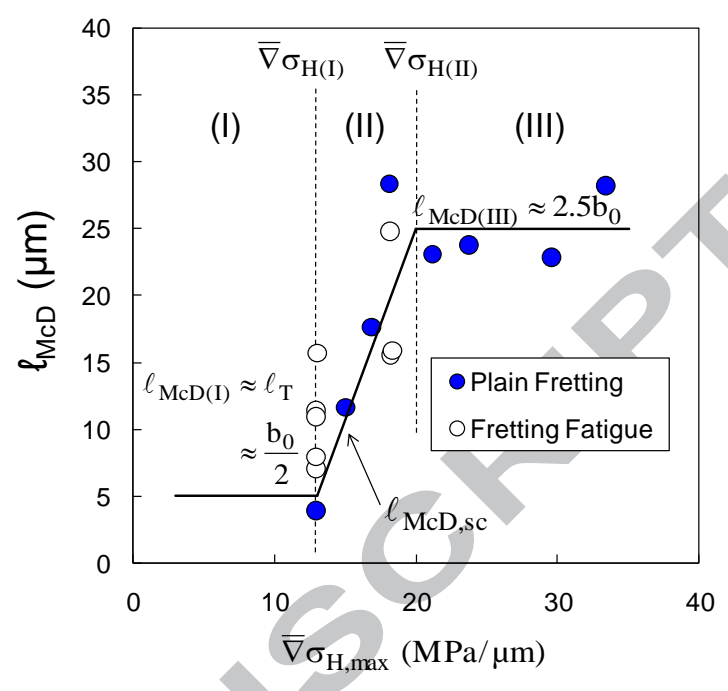

(b)

Fig. 17: Evolution of critical distance as a function of the applied hydrostatic stress gradient: (a)

MWCM criterion reverse identification, (b) McDiarmid criterion reverse identification, (I: low stress gradient domain, II: medium stress gradient domain, III : high stress gradient domain). 
TABLES

Table I : Mechanical and fatigue properties of the sstudied 35 Ni Cr Mo 16 low-alloyed steel.

\begin{tabular}{ccccccc}
\hline $\mathrm{E}(\mathrm{MPa})$ & $v$ & $\begin{array}{c}\sigma_{\mathrm{y} 0.2 \%} \\
(\mathrm{MPa})\end{array}$ & $\sigma_{\mathrm{u}}(\mathrm{MPa})$ & $\begin{array}{c}\sigma_{\mathrm{d}}=\sigma_{\mathrm{dtc}(-1)} \\
(\mathrm{MPa})\end{array}$ & $\begin{array}{c}\tau_{\mathrm{d}}=\tau_{\mathrm{d}(-1)} \\
(\mathrm{MPa})\end{array}$ & $\begin{array}{c}\Delta \mathrm{K}_{0} \\
(\mathrm{MPa} \sqrt{\mathrm{m}})\end{array}$ \\
\hline 205000 & 0.3 & 950 & 1130 & 575 & 386 & 3.2
\end{tabular}

E: Young's modulus; $v$ : Poisson's coefficient, $\sigma_{\mathrm{y} 0.2 \%}$ : Yield stress $(0.2 \%) ; \sigma_{\mathrm{u}}$ : ultimate stress; $\sigma_{\mathrm{d}}$ : traction - compression fatigue limit $\left(\mathrm{R} \sigma=\sigma_{\min } / \sigma_{\max }=-1,10^{7}\right.$ cycles $) ; \tau_{\mathrm{d}}$ : shear fatigue limite $(\mathrm{R} \tau=-1$, $10^{7}$ cycles); $\Delta \mathrm{K}_{0}$ : long crack threshold $(\mathrm{R}=-1)$.

Table II : Compilation of the studied test conditions (PF: plain fretting, FF: fretting fatigue).

\begin{tabular}{|l|c|c|c|c|c|c|c|c|c|c|c|c|c|c|c|c|c|}
\hline & $\begin{array}{c}\mathrm{R} \\
(\mathrm{mm})\end{array}$ & $\begin{array}{c}\mathrm{L} \\
(\mathrm{mm})\end{array}$ & $\begin{array}{c}\mathrm{P} \\
(\mathrm{N} / \mathrm{mm})\end{array}$ & $\begin{array}{c}\sigma_{\mathrm{fa}} \\
(\mathrm{MPa})\end{array}$ & $\mathrm{R}_{\mathrm{fa}}$ & $\begin{array}{c}\mathrm{P}_{\max } \\
(\mathrm{MPa})\end{array}$ & $\mathrm{a}(\mathrm{mm})$ & $\mu_{\mathrm{t}}$ & $\begin{array}{c}\mathrm{Q}_{\mathrm{CN}}^{*} \\
(\mathrm{~N} / \mathrm{mm})\end{array}$ & $\mathrm{k}=\frac{\mathrm{c}}{\mathrm{a}}$ & $\mathrm{h}=\frac{\mathrm{e}}{\mathrm{a}}$ & $\frac{\sigma_{\mathrm{VM}}}{\sigma_{\mathrm{Y}}}$ & $\begin{array}{c}\sigma_{\mathrm{fr}} \\
(\mathrm{MPa})\end{array}$ & $\begin{array}{c}\bar{\nabla} \sigma_{\mathrm{H}, \mathrm{max}} \\
(\mathrm{MPa} / \mu \mathrm{m})\end{array}$ & $\begin{array}{c}\ell_{\mathrm{C}} \\
(\mu \mathrm{m})\end{array}$ & $\begin{array}{c}\ell_{\mathrm{McD}} \\
(\mu \mathrm{m})\end{array}$ & $\begin{array}{c}\ell_{\mathrm{MW}} \\
(\mu \mathrm{m})\end{array}$ \\
\hline PF_1 & 20 & 3 & 353 & 0 & 0 & 800 & 0.28 & 0.8 & 186 & 0.58 & - & 0.97 & 1039 & 29.6 & 17.5 & 22.81 & 14.77 \\
\hline PF_2 & 20 & 3 & 552 & 0 & 0 & 100 & 0.35 & 0.8 & 218 & 0.71 & - & 1.05 & 1125 & 33.4 & 20.5 & 28.15 & 24.17 \\
\hline PF_3 & 40 & 5 & 398 & 0 & 0 & 600 & 0.42 & 0.85 & 271 & 0.38 & - & 0.83 & 887 & 18.0 & 17.97 & 28.39 & 24.4 \\
\hline PF_4 & 40 & 5 & 707 & 0 & 0 & 800 & 0.56 & 0.88 & 287 & 0.70 & - & 0.85 & 913 & 21.1 & 15.94 & 23.11 & 19.55 \\
\hline PF_5 & 40 & 5 & 1100 & 0 & 0 & 1000 & 0.70 & 0.75 & 310 & 0.80 & - & 0.89 & 949 & 23.8 & 16.04 & 23.72 & 19.9 \\
\hline PF_6 & 80 & 8 & 795 & 0 & 0 & 600 & 0.84 & 0.79 & 305 & 0.72 & - & 0.62 & 665 & 12.9 & 1.24 & 3.86 & 2.62 \\
\hline PF_7 & 80 & 8 & 1414 & 0 & 0 & 800 & 1.12 & 0.78 & 399 & 0.80 & - & 0.71 & 761 & 15.0 & 7.14 & 11.66 & 8.78 \\
\hline PF_8 & 80 & 8 & 2209 & 0 & 0 & 1000 & 1.40 & 0.74 & 470 & 0.85 & - & 0.77 & 826 & 16.9 & 12.08 & 17.67 & 11.29 \\
\hline FF_1 & 80 & 8 & 795 & 100 & 0.1 & 600 & 0.84 & - & 273 & 0.75 & 0.023 & 0.69 & 640 & 13 & 3.03 & 6.97 & 6.97 \\
\hline FF_2 & 80 & 8 & 795 & 200 & 0.1 & 600 & 0.84 & - & 261 & 0.76 & 0.046 & 0.78 & 637 & 13 & 8.17 & 11.31 & 11.31 \\
\hline FF_3 & 80 & 8 & 795 & 400 & 0.1 & 600 & 0.84 & - & 137 & 0.88 & 0.093 & 0.87 & 525 & 13 & 8.02 & 15.71 & 20.83 \\
\hline FF_4 & 40 & 8 & 398 & 100 & 0.1 & 600 & 0.42 & - & 210 & 0.58 & 0.023 & 0.83 & 785 & 18.1 & 12.05 & 15.5 & 15.2 \\
\hline FF_5 & 40 & 8 & 398 & 200 & 0.1 & 600 & 0.42 & - & 192 & 0.62 & 0.046 & 0.90 & 757 & 18.2 & 15.48 & 24.74 & 24.74 \\
\hline FF_6 & 40 & 8 & 398 & 400 & 0.1 & 600 & 0.42 & - & 100 & 0.83 & 0.093 & 0.93 & 596 & 18.4 & 9.55 & 15.9 & 25.42 \\
\hline FF_7 & 80 & 8 & 795 & 200 & 1 & 600 & 0.84 & - & 300 & 0.72 & - & 0.80 & 659 & 12.95 & 3.18 & 7.97 & \\
\hline FF_8 & 80 & 8 & 795 & 400 & 1 & 600 & 0.84 & - & 280 & 0.74 & - & 0.97 & 637 & 12.97 & 4.51 & 10.89 & \\
\hline
\end{tabular}


$>$ We define new fretting charts to describe the fretting fatigue crack nucleation

$>$ Non local fatigue approaches are required to consider stress gradient effects

> Constant critical distance approaches fail to provide low dispersive predictions

$>$ The optimal critical distance length varies with the hydrostatic stress gradient

$>$ New variable critical distance approaches reduce the dispersion from $16 \%$ to $4 \%$ 